NBER WORKING PAPER SERIES

\title{
BALANCE-SHEET DIVERSIFICATION IN GENERAL EQUILIBRIUM: IDENTIFICATION AND NETWORK EFFECTS
}

\author{
Jonas Heipertz \\ Amine Ouazad \\ Romain Rancière \\ Natacha Valla \\ Working Paper 23572 \\ http://www.nber.org/papers/w23572
NATIONAL BUREAU OF ECONOMIC RESEARCH
1050 Massachusetts Avenue
Cambridge, MA 02138
July 2017

The views expressed herein are those of the authors and do not necessarily reflect the views of the National Bureau of Economic Research.

At least one co-author has disclosed a financial relationship of potential relevance for this research. Further information is available online at http://www.nber.org/papers/w23572.ack

NBER working papers are circulated for discussion and comment purposes. They have not been peer-reviewed or been subject to the review by the NBER Board of Directors that accompanies official NBER publications.

(C) 2017 by Jonas Heipertz, Amine Ouazad, Romain Rancière, and Natacha Valla. All rights reserved. Short sections of text, not to exceed two paragraphs, may be quoted without explicit permission provided that full credit, including $\odot$ notice, is given to the source. 
Balance-Sheet Diversification in General Equilibrium: Identification and Network Effects Jonas Heipertz, Amine Ouazad, Romain Rancière, and Natacha Valla

NBER Working Paper No. 23572

July 2017

JEL No. G11,G15,G23

\section{ABSTRACT}

The paper uses disaggregated data on asset holdings and liabilities to estimate a general equilibrium model where each institution determines the diversification and size of the asset and liability sides of its balance-sheet. The model endogenously generates two types of financial networks: (i) a network of institutions when two institutions share common asset or liability holdings or when an institution holds an asset that is the liability of another. In both cases demand/supply decisions by one institution affect the value of other institutions' holdings/ liabilities, (ii) a network of financial instruments implied by the distribution of assets and liabilities within and across institutions. A change in the price of one asset induces change in demand/supply for all other assets, thus generating price comovement. The general equilibrium analysis predicts the propagation of real, financial and regulatory shocks as well as the change in the network caused by the shock.

Jonas Heipertz

Paris School of Economics

jonpertz@gmail.com

Amine Ouazad

HEC Montreal

3000, Chemin de la Cote Sainte Catherine

H3T 2A7, Montreal, QC

Canada

aouazad@gmail.com
Romain Rancière

Department of Economics

University of Southern California

Los Angeles, CA 90097

and NBER

ranciere@usc.edu

Natacha Valla

European Investment Bank

Natacha.Valla@eui.eu 


\section{Introduction}

The crisis of 2007-2008 has triggered considerable interest in the understanding of the role of financial networks in the propagation of financial and real shocks, and in the emergence of systemic risk in financial systems. When institutions share a common set of financial assets and liabilities, price externalities make asset demand and supply decisions interdependent across institutions. The resulting networks of institutions propagate shocks and potentially generate financial fragility such as fire-sale spirals that weaken balance sheets. Alternatively, the distribution of assets across and within institutions makes asset valuation interdependent and the resulting network of financial instruments can trigger large asset price comovement even between very different classes of assets. In contrast with network propagation associated with bilateral exposure (i.e. counterparty risk) which could be contained ex-post by targeted interventions, and prevented ex-ante by the development of centrally-cleared markets, network propagation associated with price externalities is much harder to contain.

While there is a large literature that characterizes the topology of such networks and their associated fragility (Greenwood, Landier \& Thesmar 2015, Acemoglu, Ozdaglar \& Tahbaz-Salehi 2015), their endogenous formation through market interaction and trade in financial assets is still poorly understood. ${ }^{1}$

This paper puts forward and estimates a new framework which explains how both a network of institutions and a network of financial instruments emerge out of a structural general equilibrium model of trade in financial assets and liabilities among heterogeneous institutions. The structural estimation of the model uses a dynamic factor structure for the net demand of each asset of each institution (i.e. gross demand for the asset minus liability of the same asset). This enables an identification of institutions' key characteristics: risk-aversion, cost of equity, and beliefs about future returns. The equilibrium net asset positions jointly determine both a network of financial instruments and a network of institutions. The structural estimation enables us to relate the shape of both networks and the implied shock transmission to the characteristics and beliefs of the underlying institutions. The structural approach also enables us to run counterfactual experiments. Such experiments provide an understanding of the evolution of the financial networks' structures and of their shock transmission properties, in response to changes in capital requirements,

\footnotetext{
${ }^{1}$ By contrast, there is an established literature that looks at the endogenous formation of social networks (Jackson \& Watts 2002, Goyal \& Vega-Redondo 2005)
} 
changes in the structure of shocks, and changes in institutions' beliefs. This paper is to the best of our knowledge the first to provide a direct structural link between net financial asset trade in general equilibrium, network structure, and network effects.

In this version of the paper, the model is estimated on detailed flows of funds information available for seven sectors of the French economy including a "rest of the world" sector. In such estimation, an institution represents a sector. A subsequent version will include a finer estimation based on detailed balance-sheets of individual institutions. ${ }^{2}$ The sectoral balance-sheets provide information on 20 classes of assets and liabilities, including traded securities, non-traded financial assets (e.g. loans), and real assets.

The estimation procedure follows two steps. In the first step, net asset demands by institutional sector are estimated using a dynamic factor model. Both the factor structure and the loadings are allowed to vary across institutional sectors. The key finding is that a small number of factors is able to explain the bulk of the variance in net demands. Moreover, the factors exhibit a close correspondence with drivers of the Global cycle and Eurozone cycle, as they respectively correlate with US and Euro policy rates, global GDP growth and global trade growth, the VIX measure of implied global risk aversion, or interest rates on government securities for the countries that were subject to the sovereign crisis of 2011 (Greece, Ireland, Italy, Portugal and Spain). In the second step, the structural parameters of the net asset demand model regarding institutions characteristics (risk aversion and the cost of equity) and return beliefs, are obtained, through a mapping between the factor structure of net demand and the factor structure of return beliefs. Finally, a set of closed-form formulas enables then to fully characterize the network structure and to obtain general equilibrium effects associated with a diffusion of a sector-specific shock in the network.

A first set of results regards the analysis of return beliefs across institutions and across assets. The model for return beliefs indeed explains up to 39 percent of the variance of ex-post returns depending on the sector and instrument. Moreover, the cases when the belief model fails to predict return are almost all related to the 2007-2008 crisis when some institutional sectors made counter-cyclical net asset purchases, i.e. buying assets whose returns are declining, for liquidity reasons (banking sector) or bailout purposes (public sector).

A second set of results emerges from the analysis of the dual network of assets and

\footnotetext{
${ }^{2}$ The clearance for these confidential data has been obtained too late so that this estimation could be included on this graph.
} 
institutions, and its implications for shock propagation. Network effects stemming from the general equilibrium impact of a shock to the capital base of the banking sector on all sectors including he banking sector itself reveal that: (i) such effects can be sizeable and, in some sectors, of comparable - if not amplified - magnitude than those experienced by the sector where the shock originated; (ii) they vary dramatically in size and scope across sectors. This evidence vindicates the massive net asset demand shifts - out of banks into the insurance sector - that could be observed in the aftermath of the 2007-2008 crisis as a result of severe capital losses in the banking sector that preceded the euro sovereign crisis.(Heipertz, Ranciere \& Valla 2016).

This paper builds a bridge between two literatures, the literature on asset demand among heterogeneous institutions (Koijen \& Yogo 2016, Miranda-Agrippino \& Rey 2015) and that on financial networks structure and associated network effects (Eisenberg \& Noe 2001, Elliott, Golub \& Jackson 2014, Greenwood et al. 2015). The paper develops a novel methodology that uses balance sheet information on asset and liability positions of all sectors of the economy to estimate structurally a general equilibrium model of net asset demand allowing for large sectoral heterogeneity in risk-aversion, beliefs, and cost of equity. The estimated model generates endogenously a time-varying network of financial instrument and a network of institutional sectors.

Another innovation of the paper is to use the full balance sheet of asset and liability for all sectors of the French economy rather than focusing on asset allocation for just one sector, such as the mutual fund sector. This approach turns out to be important as the 2007-2008 crisis generated considerable reshuffling in liability and asset positions across sectors. In the case of France, the crisis of 2007-2008 led to a retrenchment of the banking sector accompanied for an expansion of the insurance sector (Heipertz et al. 2016). While the use of sector-level data allows to assess the general equilibrium effect of a sectoral shock on the very same sector, it does not account for the role played by large net demand position of individual institutions that net out at the sector level. Until the issue is addressed with the use of individual institutional data, the network effects measured here could be considered as conservative estimates of the importance of financial networks in the propagation of shocks.

The paper contributes to the literature on the role of belief heterogeneity in asset pricing (Berrada 2006, Gandhi \& Serrano-Padial 2015) by using net asset demands to estimate a model with a large dimension of heterogeneity (risk-aversion, beliefs, cost of equity). The paper shares with Koijen \& Yogo (2016) the objective of a structural model 
that simultaneously matches asset demands and imposes market clearing but our approach is very different. Rather than estimating a discrete choice model to understand the portfolio choice of investors as a function of characteristics, we are using the factor structure of net demands for assets to reveal the factor structure of the beliefs about asset returns and other structural parameters. Price externalities are at the core of our network of institutions and network of financial instruments as in Greenwood et al. (2015) but with the key difference that the networks in our paper are derived from a general equilibrium model of net asset trade rather than just assumed. In additon Greenwood et al. (2015) only deal common asset holdings accross institutions when we also consider the role of assets and liabilities holdings for the propagation of shocks. The factor structure of net demands emphasizes the role of the global cycle as in Miranda-Agrippino \& Rey (2015) but also stresses the importance of Euro area specific factors in the dynamics of net demand.

\section{Theoretical Framework}

\subsection{The Model}

A finite number $N$ of firms trade $J$ financial instruments in each discrete time period $t=1,2,3, \ldots$. In period $t$, each of the $j=1,2, \ldots, J$ financial instruments has a price $p_{j t}$ and yields a stochastic return $\widetilde{r_{j t}}$ at the end of the period.

Each firm $i$ has a level of equity $E_{i t}$ in period $t$ and seeks to maximize the expected return on its equity by raising funds on the market (through the emission of liabilities) and investing these raised funds and the firm's equity in financial and real assets. Thus, each firm $i$ chooses a level of gross demand $D_{i j t}$ and gross supply $S_{i j t}$ for each of the $J$ financial instruments. Each additional unit of total demand for assets beyond the initial level equity $E_{i j t}$ requires raising a corresponding additional unit of liability. Indeed, the firm's balance sheet satisfies the usual equality of assets and liabilities, formally:

$$
\mathbf{D}_{i t}^{\prime} \mathbf{1}_{J}=\mathbf{S}_{i t}^{\prime} \mathbf{1}_{J}+E_{i t}
$$

where $\mathbf{D}_{i t}=\left(D_{i 1 t}, \ldots, D_{i 2 t}\right)^{\prime}$ is the column vector of demands for each of the $J$ instruments, and $\mathbf{S}_{i t}$ is the column vector of supplies. $\mathbf{1}_{J}$ is the column vector of ones of size $J$. Such demand and supply choices, together with firm $i$ 's initial equity level, make up both total balance sheet size and its asset and liability diversification.

In order to maximize its return on equity, each firm $i$ forms beliefs about the distribu- 
tion of future returns $\widetilde{r_{j t}}$ based on (i) a firm-specific and potentially sophisticated return forecasting model, and (ii) on a firm-specific information set. Both model and information are fundamentally unobservable to the econometrician. Such firm-specific forecasting exercise yields a distribution of returns noted $\widetilde{r_{i j t}}$. We will assume throughout that stochastic beliefs about returns are not multicollinear and have strictly positive variances, which implies that the variance-covariance of beliefs is symmetric, positive-definite. Noting $\widetilde{\mathbf{r}_{i t}}$ the firm-specific stochastic belief about returns, the firm's net income is $\left(\mathbf{D}_{i t}-\mathbf{S}_{i t}\right)^{\prime} \widetilde{\mathbf{r}_{i t}}$.

Each firm trades off the expected return and the expected variance of such stochastic net income. The relative importance of variance for firm $i$ is noted $\rho_{i} \cdot{ }^{3}$ Alternatively, firms can also maximize expected returns under a value-at-risk (VAR) constraint, where the lagrange multiplier corresponding to such constraint is equivalently noted $\rho_{i}$. Formally firm $i$ demands and supplies assets in order to maximize

$$
\left(\mathbf{D}_{i t}-\mathbf{S}_{i t}\right)^{\prime} \boldsymbol{\mu}_{i t}-\frac{1}{2} \rho_{i}\left(\mathbf{D}_{i t}-\mathbf{S}_{i t}\right)^{\prime} \boldsymbol{\Sigma}_{i t}\left(\mathbf{D}_{i t}-\mathbf{S}_{i t}\right)
$$

where $\boldsymbol{\mu}_{i t} \equiv E\left[\widetilde{\boldsymbol{r}_{i t}}\right] \equiv E\left[\widetilde{\boldsymbol{r}_{t}} \mid \Omega_{i t}\right]$ is the $J$-vector of mean return beliefs and $\boldsymbol{\Sigma}_{i t} \equiv \operatorname{Var}\left[\widetilde{\boldsymbol{r}_{i t}}\right] \equiv$ $\operatorname{Var}\left[\widetilde{\boldsymbol{r}}_{t} \mid \Omega_{i t}\right]$ is the $J$-square matrix of the variance-covariance of return beliefs. Both are obtained by firm $i$ given its information set and model, noted $\Omega_{i t}$. The maximization of (2) is performed under the funding constraint (1), as the total amount of outstanding assets must equal the sum of initial equity and funds raised.

\subsection{Net Demands and Cost of Equity}

There exists a closed form solution for the balance sheet that maximizes the mean-variance objective under the funding constraint as described in the following proposition.

Proposition 1. Each institution i's net demand for assets depends on the first two moments of its return beliefs, its risk aversion, and its cost of capital. Formally, write $\boldsymbol{\Delta}_{i t}=\mathbf{D}_{i t}-\mathbf{S}_{i t}$ the J-vector of net demands, then

$$
\boldsymbol{\Delta}_{i t}=\mathbf{D}_{i t}-\mathbf{S}_{i t}=\frac{1}{\rho_{i}} \boldsymbol{\Sigma}_{i t}^{-1}\left(\boldsymbol{\mu}_{i t}-\eta_{i t} \mathbf{1}\right)
$$

\footnotetext{
${ }^{3}$ This mean-variance goal for a firm formally corresponds to the concept of absolute risk aversion in the context of household choice under uncertainty with Constant Absolute Risk Aversion (CARA).
} 
where $\eta_{i t}$ is the scalar Lagrange multiplier of the funding constraint,

$$
\eta_{i t}=\frac{\mathbf{1}^{\prime} \boldsymbol{\Sigma}_{i t}^{-1} \boldsymbol{\mu}_{i t}-\rho_{i} E_{i t}}{\mathbf{1}^{\prime} \boldsymbol{\Sigma}_{i t}^{-1} \mathbf{1}} .
$$

The Lagrange multiplier $\eta_{i t}$ corresponding to constraint (1) is the cost of equity as the marginal impact of an additional unit of equity in period $t$ on the firm's mean-variance objective (2).

\subsection{Market Equilibrium}

The previous section has obtained the net demand of each financial instrument as a function of (i) return beliefs, (ii) risk aversion and (iii) firm equity. While the beliefs about end-ofperiod returns are institution-specific (each institution estimates a forecast of returns), the asset price $p_{j t}$ is public information. In that sense, the uncertainty of a financial institution is over future dividends and future asset values, not about the current price of the asset.

$$
\widetilde{r_{i j t}}=\frac{E\left[\widetilde{p_{j t+1}}+\widetilde{d_{j t+1}} \mid \Omega_{i t}\right]}{p_{j t}}
$$

where $\widetilde{p_{j t+1}}$ is the price in period $t+1, \widetilde{d_{j t+1}}$ the dividend in period $t+1$ and $\Omega_{i t}$ the information set of institution $i$ in period $t$. Thus net demand (3) is a function of asset prices, and defines demand and supply curves for all instruments and all institutions.

To define an equilibrium, notice that the equity of firm $i$ is a financial instrument $j(i) \in\{1,2, \ldots, J\}$ supplied by firm $i$ and demanded by (potentially) all other firms $i^{\prime} \neq i$, so that equilibrium on the market for the equity $j(i)$ of firm $i$ is $\sum_{i^{\prime}=1}^{N} \Delta_{i^{\prime} j(i) t}=E_{i t}$. On all other markets, the equilibrium condition is: $\sum_{i^{\prime}=1}^{N} \Delta_{i^{\prime} j t}=0$. Stack all $E_{i t}$ in a $J$-vector $\mathbf{E}_{t}$ whose $j$-th element is $E_{i t}$ if $j(i)=j$ and 0 otherwise, then:

Definition 1. An equilibrium in period $t$ is a J-vector of prices for each financial instrument $\mathbf{p}_{t}^{*}$ such that all $J$ markets clear:

$$
\sum_{i=1}^{N} \boldsymbol{\Delta}_{i t}\left(p_{1 t}^{*}, p_{2 t}^{*}, \ldots, p_{J t}^{*}\right)=\mathbf{E}_{t}\left(p_{1 t}^{*}, p_{2 t}^{*}, \ldots, p_{J t}^{*}\right),
$$

where each $\boldsymbol{\Delta}_{i t}\left(\mathbf{p}_{t}^{*}\right)$ is a column vector of size $J$; the institution-specific equilibrium vectors of net demands are $\boldsymbol{\Delta}_{i t}^{*} \equiv \boldsymbol{\Delta}_{i t}\left(p_{1 t}^{*}, p_{2 t}^{*}, \ldots, p_{J t}^{*}\right)$; and $\mathbf{E}_{t}\left(\mathbf{p}_{t}^{*}\right)$ is a column vector of size $J$. 
The equilibrium in such an economy exists, as shown in the following proposition:

Proposition 2. (Existence of an Equilibrium) There exists a price vector $\mathbf{p}_{t}^{*} \in \mathbb{R}^{J}$ such that $\sum_{i=1}^{N} \boldsymbol{\Delta}_{i t}\left(\mathbf{p}_{t}^{*}\right)=\mathbf{E}_{t}\left(\mathbf{p}_{t}^{*}\right)$.

An extension of the framework where the net demand vector includes $J^{\text {exo }}$ exogenous net demands (i.e. unaffected by prices), and $J^{\text {endo }}$ endogenous net demands (i.e. defined as in equation (3)), yields a similar result on the existence of equilibrium prices and net demands.

\subsection{Shock Propagation with Comparative Statics}

The general equilibrium setting enables an analysis of propagation of a shock on fundamentals or beliefs. Indeed shocks cause shifts in individual firm net demands, which affect market prices, and thus potentially all net demands in the economy. The general equilibrium analysis with comparative statics provides two dual networks, as shocks propagate through (i) the network of financial instruments' prices, and through (ii) the network of institutions' balance sheets.

\subsubsection{Comparative Statics}

Consider a shock $d \theta$ on one of the economy's structural exogenous parameters $\theta$. Possible shocks $d \theta$ include shifts in the equity of a financial institution, shifts in the beliefs about future returns, shifts in exogenous net demands, shifts in risk aversion, or the introduction of a liquidity or capital constraint. The shock $d \theta$ can affect one or more institutions.

The total impact of a shock $d \theta$ on the net demand of each institution $i=1,2, \ldots, N$ in year $t$ is the sum of a partial equilibrium term, and a general equilibrium term. Indeed, the total derivative of net demand w.r.t. the shock expands according to the chain rule as: ${ }^{4}$

$$
\frac{d \boldsymbol{\Delta}_{i t}}{d \theta}=\frac{\partial \boldsymbol{\Delta}_{i t}}{\partial \theta}+\frac{\partial \boldsymbol{\Delta}_{i t}}{\partial \log \mathbf{p}_{t}} \frac{d \log \mathbf{p}_{t}}{d \theta}
$$

where $\frac{\partial \boldsymbol{\Delta}_{i t}}{\partial \theta}$ is the partial equilibrium effect, and $\frac{\partial \boldsymbol{\Delta}_{i t}}{\partial \log \mathbf{p}_{t}}$ the sensitivity of net demand to the prices of financial instruments. $\frac{d \log \mathbf{p}_{t}}{d \theta}$ is the market-wide shift in the vector of log prices,

\footnotetext{
${ }^{4}$ For the sake of clarity, we are considering a shock that does not affect equity directly, i.e. $\partial E_{i t} / \partial \theta=0$. If the shock has a direct impact on equity, the total derivative of net demand with respect to the shock is $\frac{d \boldsymbol{\Delta}_{i t}}{d \theta}=\frac{\partial \boldsymbol{\Delta}_{i t}}{\partial \theta}+\frac{\partial \boldsymbol{\Delta}_{i t}}{\partial \log \mathbf{p}_{t}} \frac{d \log \mathbf{p}_{t}}{d \theta}+\frac{\partial \boldsymbol{\Delta}_{i t}}{\partial E_{i t}} \frac{\partial E_{i t}}{\partial \theta}$. The following analysis can proceed in a similar fashion, adding the term $\left(\partial \boldsymbol{\Delta}_{i t} / \partial E_{i t}\right) \cdot\left(\partial E_{i t} / \partial \theta\right)$ to the right-hand side of equation 7 .
} 
common to all institutions.

Starting from a market equilibrium $\left(\mathbf{p}^{*},\left(\boldsymbol{\Delta}_{i t}^{*}, i=1,2, \ldots, I, t=1,2, \ldots, T\right)\right)$, the shock $d \theta$ affects net demands in a way that violates the equilibrium condition (6). The shift in prices $d \log \mathbf{p}_{t} / d \theta$ is the vector of price changes that restores equilibrium in each market. Then the equality of shifts in demand and shifts in equity values,

$$
\sum_{k=1}^{N}\left[\frac{\partial \boldsymbol{\Delta}_{k t}}{\partial \theta}+\frac{\partial \boldsymbol{\Delta}_{k t}}{\partial \log \mathbf{p}_{t}} \frac{d \log \mathbf{p}_{t}}{d \theta}\right]=\frac{\partial \mathbf{E}_{t}}{\partial \log \mathbf{p}_{t}} \frac{d \log \mathbf{p}_{t}}{d \theta}
$$

provides the general equilibrium price shift $d \log \mathbf{p}_{t} / d \theta$ :

$$
\frac{d \log \mathbf{p}_{t}}{d \theta}=\left[\frac{\partial \mathbf{E}_{t}}{\partial \log \mathbf{p}_{t}}-\sum_{k=1}^{N} \frac{\partial \boldsymbol{\Delta}_{k t}}{\partial \log \mathbf{p}_{t}}\right]^{-1}\left[\sum_{k=1}^{N} \frac{\partial \boldsymbol{\Delta}_{k t}}{\partial \theta}\right],
$$

In the short run, with a fixed number of shares in each firm $i$, equity is unit-elastic with respect to $\log$ prices and $\partial \mathbf{E}_{t} / \partial \log \mathbf{p}_{t}$ is diagonal with entries $\mathbf{E}_{t}$.

Using shifts in $\log$ prices $d \log \mathbf{p}_{t}$ is less convenient empirically than using shifts in $\log$ returns $d \log \mathbf{r}_{i t}$. Indeed, the price of an asset can vary over time for reasons unrelated to market demand or supply, such as because of a stock split. Here a given log change in price $p_{i j t}$, at fixed information set $\Omega_{i t}$, corresponds to the same magnitude of log change in returns. Indeed, as only the payoff part of returns is institution-specific in the definition of returns (5),

$$
-d \log r_{i j t}=d \log p_{j t}
$$

the change in log return is independent of the identity of institution $i$.

The total impact of the shock (7) can be expressed in terms of shocks to log prices instead of absolute prices, and thus can be expressed in terms of minus log returns. Finally, the impact of the shock $d \theta$ on the $J$-vector of net demands of institution $i$ is:

$$
\frac{d \boldsymbol{\Delta}_{i t}}{d \theta}=\underbrace{\frac{\partial \boldsymbol{\Delta}_{i t}}{\partial \theta}}_{\text {Partial }}+\underbrace{\frac{\partial \boldsymbol{\Delta}_{i t}}{\partial \log \mathbf{r}_{i t}}\left[\frac{\partial \mathbf{E}_{t}}{\partial \log \mathbf{p}_{t}}-\sum_{k=1}^{N} \frac{\partial \boldsymbol{\Delta}_{k t}}{\partial \log \mathbf{r}_{i t}}\right]^{-1} \sum_{k=1}^{N} \frac{\partial \boldsymbol{\Delta}_{k t}}{\partial \theta}}_{\text {General }}
$$

where all terms can be derived from the closed-form expression for net demands presented in equation (3). 


\subsubsection{Network of Financial Instruments}

The general equilibrium effect described in equation (11) provides this paper's microfoundation of a network of assets. To see this, notice that the propagation of partial equilibrium shocks in (11) crucially depends on the inverse of the price sensitivity of net demands to log returns:

$$
\left[\frac{\partial \mathbf{E}_{t}}{\partial \log \mathbf{r}_{t}}-\sum_{k=1}^{N} \frac{\partial \boldsymbol{\Delta}_{k t}}{\partial \log \mathbf{r}_{t}}\right]^{-1} \equiv\left[\frac{\partial \mathbf{E}_{t}}{\partial \log \mathbf{r}_{t}}\right]^{-1}\left[\mathbf{1}-A_{t}\right]^{-1},
$$

where noting ${ }^{5} A_{t} \equiv\left[\frac{\partial \mathbf{E}_{t}}{\partial \log \mathbf{r}_{t}}\right]^{-1}\left[\sum_{k=1}^{N} \frac{\partial \boldsymbol{\Delta}_{k t}}{\partial \log \mathbf{r}_{k t}}\right]$ enables a description of the inverse as the sum of :

$$
\left(1-A_{t}\right)^{-1}=1+A_{t}+A_{t}^{2}+A_{t}^{3}+\ldots,
$$

Consider $\left(d \boldsymbol{\Delta}_{i t} / d \theta\right)^{S}$ the effect of the shock $d \theta$ taking into account only the sum of the powers of $A_{t}$ up to order $S$ :

$$
\left(\frac{d \boldsymbol{\Delta}_{i t}}{d \theta}\right)^{s}=\frac{\partial \boldsymbol{\Delta}_{i t}}{\partial \theta}+\frac{\partial \boldsymbol{\Delta}_{i t}}{\partial \log \mathbf{r}_{i t}}\left[\frac{\partial \mathbf{E}_{t}}{\partial \log \mathbf{r}_{t}}\right]^{-1}\left(\sum_{s=0}^{S} A_{t}^{s}\right)\left[\sum_{k=1}^{N} \frac{\partial \boldsymbol{\Delta}_{k t}}{\partial \theta}\right],
$$

Then $\lim _{S \rightarrow \infty}\left(d \boldsymbol{\Delta}_{i t} / d \theta\right)^{S}=\left(d \boldsymbol{\Delta}_{i t} / d \theta\right)^{\infty}$ is the general equilibrium impact of the shock $d \theta$. $\left(d \boldsymbol{\Delta}_{i t} / d \theta\right)^{S}$ is thus the impact of the shock $d \theta$ accounting for the $S$-th level propagation of shocks across the financial network.

Definition 2. The network of financial instruments is a weighted and directed graph $\mathcal{G}_{f i}$ whose vertices are financial instruments and:

1. There is an edge from financial instrument $j$ to financial instrument $j^{\prime}$ if a shift in the return of financial instrument $j$ affects the economy's net demand for financial instrument $j^{\prime}$,

2. The weight of the edge $\left(j, j^{\prime}\right)$ is the opposite of the semi-elasticity of economy-wide net demand for $j^{\prime}$ w.r.t. the log return of $j$, up to a constant.

The adjacency matrix of such a graph over financial instruments is $A_{t}$. The adjacency matrix of the graph of $S$-level connections is $A_{t}^{s}$.

\footnotetext{
${ }^{5}$ with a fixed equity in the short-run, $\left[\partial \mathbf{E}_{t} / \partial \log \mathbf{p}_{t}\right]^{-1}$ is diagonal with entries $\operatorname{diag}\left(1 / \mathbf{E}_{t}\right)$ and $A_{t}$ is the impact of log returns on net demand as a fraction of equity.
} 
The network of financial instruments captures two different types of linkages. First, it captures linkages between assets and liabilities in the same institution. Two assets $j, j^{\prime}$ are indeed connected if one is the asset of an institution $k$ and the other is the liability of the same institution. In such a case $\Delta_{k j t}$ and $\Delta_{k j^{\prime} t}$ are of opposite signs, $\Delta_{k j t} \Delta_{k j^{\prime} t}<0$. Second, the network of assets also captures linkages due to the common holding of the two assets (or the common supply of the two liabilities). Two assets are connected if both are assets (or both are liabilities) of the same institution $k$. In such a case $\Delta_{k j t}$ and $\Delta_{k j^{\prime} t}$ are of the same sign, $\Delta_{k j t} \Delta_{k j^{\prime} t}>0$.

The adjacency matrix $A_{t}$ of the network of financial instruments can be broken down into two networks that correspond to each of the two types of linkages, asset-liability linkages and common-holding linkages. The matrix $A_{t}^{a l}$ of asset-liability linkages is:

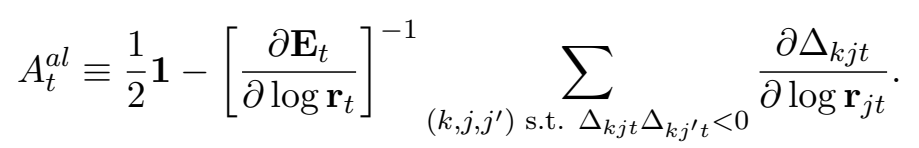

Similarly, the corresponding matrix $A_{t}^{c h}$ of common-holding linkages takes the sum of the semi-elasticities over the set of triplets $\left(k, j, j^{\prime}\right)$ for which $\Delta_{k j t} \Delta_{k j^{\prime} t} \geq 0$. Then the adjacency matrix of financial instruments is the sum of the two networks:

$$
A_{t}=A_{t}^{a l}+A_{t}^{c h}
$$

\subsubsection{Network of Institutions}

A dual network of institutions corresponds to the network of assets described in the previous subsection. To find the network of institutions, for clarity of exposition, we start by considering a shock $d \theta_{k}$ that affects the net demand of only one institution $k$, and consider the impact of that shock on any other institution's equity. This yields an effect for any pair of institutions, leading to an adjacency matrix for institutions.

The impact of the institution-specific shock on any other institution $k^{\prime}$ 's net demands is:

$$
\frac{d \boldsymbol{\Delta}_{k^{\prime} t}}{d \theta_{k}}=\frac{\partial \boldsymbol{\Delta}_{k^{\prime} t}}{\partial \theta_{k}}+\frac{\partial \boldsymbol{\Delta}_{k^{\prime} t}}{\partial \log \mathbf{r}_{k t}}\left[\frac{\partial \mathbf{E}_{t}}{\partial \log \mathbf{r}_{t}}-\sum_{i=1}^{N} \frac{\partial \boldsymbol{\Delta}_{i t}}{\partial \log \mathbf{r}_{i t}}\right]^{-1} \frac{\partial \boldsymbol{\Delta}_{k t}}{\partial \theta_{k}}
$$


The impact of the shock of $k$ on institution $k^{\prime}$ 's equity is thus:

$$
\frac{d E_{k^{\prime} t}}{d \theta_{k}}=\mathbf{1}^{\prime}\left(\frac{d \boldsymbol{\Delta}_{k^{\prime} t}}{d \theta_{k}}\right)=\left(\mathbf{1}^{\prime} \frac{\partial \boldsymbol{\Delta}_{k^{\prime} t}}{\partial \log \mathbf{r}_{k^{\prime} t}}\right)\left[\frac{\partial \mathbf{E}_{t}}{\partial \log \mathbf{r}_{t}}-\sum_{i=1}^{N} \frac{\partial \boldsymbol{\Delta}_{i t}}{\partial \log \mathbf{r}_{i t}}\right]^{-1} \frac{\partial \boldsymbol{\Delta}_{k t}}{\partial \theta_{k}} \equiv \omega_{k k^{\prime}}
$$

which is the product of institution $k^{\prime}$ demand sensitivity to returns, and institution $k$ 's sensitivity to the shock. Interestingly, if there are no price effects across financial instruments, i.e. $\sum_{i=1}^{N} \frac{\partial \boldsymbol{\Delta}_{i t}}{\partial \log \mathbf{r}_{i t}}$ is a diagonal matrix, then $\omega_{k k^{\prime}} \neq 0$ only if the two institutions hold or supply at least one common financial instrument. When there are impacts of the price of instruments on the net demands of other instruments, firms can be connected even when they do not hold the same financial instruments.

The chain of causes and effects from the shock $k$ to the equity of $k^{\prime}$ takes three steps: first, a partial equilibrium effect. Institution $k$ is affected by the shock $d \theta_{k}$, measured by the rightmost term $\frac{\partial \boldsymbol{\Delta}_{k t}}{\partial \theta_{k}}$ in equation (18). The response of institution $k$ in partial equilibrium is $\partial \boldsymbol{\Delta}_{k t} / \partial \theta_{k}$. Second, a price effect. Institution $k$ 's changes in net demand cause a change in asset prices, measured by $\left[\frac{\partial \mathbf{E}_{t}}{\partial \log \mathbf{r}_{t}}\right]^{-1}\left(1-A_{t}\right)^{-1}=\left[\frac{\partial \mathbf{E}_{t}}{\partial \log \mathbf{r}_{t}}-\sum_{i=1}^{N} \frac{\partial \boldsymbol{\Delta}_{i t}}{\partial \log \mathbf{r}}\right]^{-1}$. This is the middle term in equation (18). Third, institution $k^{\prime}$ changes its net demand in response to the price change. The impact on equity is $\left(\mathbf{1}^{\prime} \frac{\partial \boldsymbol{\Delta}_{k^{\prime} t}}{\partial \log \mathbf{r}_{k^{\prime} t}}\right)$, which is the leftmost term in equation (18).

Definition 3. The network of firms is a weighted and directed graph $\mathcal{G}_{f}$, whose vertices are firms, and

1. There is an edge from firm $k$ to firm $k^{\prime}$ if the shock on firm $k$ affects the equity of firm $k^{\prime}$ in general equilibrium.

2. The weight of the edge $\left(k, k^{\prime}\right)$ is the impact in value of the shock on firm $k$ on the equity of firm $k^{\prime}$.

The adjacency matrix of such graph $\mathcal{G}_{f}$ is $\Omega=\left(\omega_{k k^{\prime}}\right)_{k, k^{\prime} \in\{1,2, \ldots, I\}}$

As in the case of the network of financial instruments, the captures two types of connections between institutions: first, asset-liability linkages, where firm $k$ and firm $k^{\prime}$ are connected if one asset of firm $k$ is the liability of firm $k^{\prime}$. Second, common-holding linkages, where firm $k$ and firm $k^{\prime}$ are connected if one asset (resp., liability) of firm $k$ is also the asset (resp., liability) of firm $k^{\prime}$. 
Then the network of institutions $\Omega$ can be decomposed into two parts: a network $\Omega^{a l}$ due to asset-liability linkages and a network $\Omega^{c h}$ due to the common holding of financial instruments.

$$
\Omega=\Omega^{a l}+\Omega^{c h}
$$

with

$$
\omega_{k k^{\prime}}^{a l}=\sum_{\left(j, k, k^{\prime}\right), \Delta_{k j t} \Delta_{k^{\prime} j t}<0}\left(\mathbf{1}^{\prime} \frac{\partial \boldsymbol{\Delta}_{k^{\prime} t}}{\partial \log r_{k^{\prime} j t}}\right)\left[\frac{\partial \mathbf{E}_{t}}{\partial \log \mathbf{r}_{t}}-\sum_{i=1}^{N} \frac{\partial \boldsymbol{\Delta}_{i t}}{\partial \log \mathbf{r}_{i t}}\right]^{-1} \frac{\partial \boldsymbol{\Delta}_{k t}}{\partial \theta_{k}}
$$

And similarly for $\omega_{k k^{\prime}}^{c h}$, where the sum is taken over $\left(j, k, k^{\prime}\right)$ s.t. $\Delta_{k j t} \Delta_{k^{\prime} j t} \geq 0$. The decomposition amounts, in product (18), to pick the pairs of assets and institution that fall in the case of asset-liability linkage or in the case of common-holding linkages. Importantly, the framework both pinpoints that there is a linkage, and microfounds the magnitude and the sign of the linkage.

\section{Identification}

\subsection{Belief Formation and Factor Structure in Net Demands}

Agents use sophisticated models and private information to forecast returns. Such information and modeling is fundamentally unobserved to the econometrician. However, following the recent literature on empirical asset pricing (Koijen \& Yogo 2016, Miranda-Agrippino \& Rey 2015) we can identify the unobservable factor structure that explains fluctuations in returns. Indeed, this section shows that (i) assuming a factor structure in firm-specific returns implies a factor structure in net demands, and (ii) the factor structure in net demands can be estimated, and (iii) the relationship from returns to net demands can be inverted to identify the factor structure in returns. Additionally, both factors and loadings are specific to each financial institution $i$ reflecting the fact that institutions have heterogeneous beliefs about both the factors that price assets and about the comovement of asset prices with factors.

The vector of ex-ante beliefs about returns is assumed to follow a factor structure:

$$
\widetilde{\boldsymbol{r}_{i t}}=\boldsymbol{\varphi}_{i}+\Lambda_{i} \mathbf{f}_{i t}+\boldsymbol{\epsilon}_{i t}, \quad \operatorname{Var}\left(\boldsymbol{\epsilon}_{i t}\right)=\sigma_{\epsilon}^{2} \mathbf{1}
$$


where $\mathbf{f}_{i t}$ is a $J \times K$ matrix of factors, $\boldsymbol{\varphi}_{i}$ is a $J$ vector of constants, $\Lambda_{i}$ is a $J \times K$ matrix of factor loadings and $\boldsymbol{\epsilon}_{i t}$ is a $J$-vector of factors unobservable to the institution and therefore capturing the uncertainty of institution $i$ about future returns. Furthermore, we assume that factors follow an autoregressive process of order one.

$$
\mathbf{f}_{i t}=\boldsymbol{\alpha}_{0}+\boldsymbol{\alpha}_{1} \mathbf{f}_{i t-1}+\boldsymbol{u}_{i t}, \operatorname{Var}\left(\boldsymbol{u}_{i t}\right)=\sigma_{u}^{2} \mathbf{1},
$$

where $\boldsymbol{\alpha}_{0}$ is a $K \times 1$ vector of factor constants, $\boldsymbol{\alpha}_{1}$ a $K \times K$ diagonal matrix of autoregressive coefficients and $\boldsymbol{u}_{i t}$ innovations to factors. Agents beliefs are thus based on a dynamic factor model and obtained in two steps. First, agents forecast tomorrow's value of the factors and second, use loadings to price assets.

Proposition 3. The dynamic factor model outlined above implies that the first and second moments of return beliefs (and therefore the full distribution) are parametrized. The optimal net demand schedule of firm $i$ can be written as

$$
\boldsymbol{\Delta}_{i t}=C_{i}+L_{i} \mathbf{f}_{i t}-\overline{\eta_{i t}} \mathbf{1}
$$

where the constant vector $C_{i}$, the loadings $L_{i}$, and the transformed cost of equity $\overline{\eta_{i t}}$ are functions of the unobserved factor structure of returns and the autoregressive dynamic of factors:

$$
C_{i}=\left(\mathbf{I}+\frac{\sigma_{u}^{2}}{\sigma_{\varepsilon}^{2}} \Lambda_{i} \Lambda_{i}^{\prime}\right)^{-1}\left[\boldsymbol{\varphi}_{i}+\Lambda_{i} \boldsymbol{\alpha}_{0}\right] /\left(\rho_{i} \sigma_{\epsilon}^{2}\right), \quad L_{i}=\left(\mathbf{I}+\frac{\sigma_{u}^{2}}{\sigma_{\varepsilon}^{2}} \Lambda_{i} \Lambda_{i}^{\prime}\right)^{-1} \Lambda_{i} \boldsymbol{\alpha}_{0} /\left(\rho_{i} \sigma_{\epsilon}^{2}\right)
$$

and the transformed cost of equity $\overline{\eta_{i t}}=\left(\mathbf{I}+\frac{\sigma_{u}^{2}}{\sigma_{\varepsilon}^{2}} \Lambda_{i} \Lambda_{i}^{\prime}\right)^{-1} \eta_{i t} /\left(\rho_{i} \sigma_{\epsilon}^{2}\right)$.

Proposition (3) shows that a factor structure of return beliefs implies a factor structure of net demands.

\subsection{Identification of ex-ante returns beliefs}

Identifying the ex-ante beliefs is finding the structural parameters $\left(\varphi_{i}, \Lambda_{i}, \alpha_{0}, \alpha_{1}, \eta_{i t}\right)$ of the dynamics of returns $\widetilde{r_{i t}}$ that match observations $\left(C_{i}, L_{i}, A_{0}, A_{1}, \overline{\eta_{i t}}\right)$ for each firm. Indeed, equation (22) in proposition 3 provides a mapping from such structural parameters to the observations. Identifying firms' beliefs about returns and their cost of equity requires inverting such relationship. 
We first show that, conditional on the overall mean $\mu$ and variance of all ex-ante returns $\sigma_{\varepsilon}^{2}$, the factor structure of each ex-ante return (constants and loadings), as well as the cost of equity for each firm $i$, are identified.

The first step is to estimate a augmented dynamic factor model on $\boldsymbol{\Delta}_{i t}$, which yields the AR dynamic of factors $\left(\alpha_{0}, \alpha_{1}, \sigma_{u}^{2}\right)$, as well as the constant and loadings $\left(\mathbf{C}_{i}, \mathbf{L}_{i}\right)$ of net demands, and the transformed cost of equity $\overline{\eta_{i t}}$.

The second step is to invert the mapping:

$$
g:\left(\frac{1}{\rho \sigma_{\varepsilon}^{2}}, \boldsymbol{\Lambda}\right) \longmapsto(\frac{\sigma_{u}^{2}}{\sigma_{\varepsilon}^{2}}, \underbrace{\frac{1}{\rho \sigma_{\varepsilon}^{2}}\left(\mathbf{1}+\frac{\sigma_{u}^{2}}{\sigma_{\varepsilon}^{2}} \boldsymbol{\Lambda} \mathbf{\Lambda}^{\prime}\right)^{-1} \boldsymbol{\Lambda}}_{\mathbf{L}_{i}}),
$$

from $\mathbb{R} \times \mathbb{R}^{J K}$ to itself, at $\sigma_{u}^{2}$ constant. We find numerically that $g$ is invertible. Then risk aversion $\rho_{i}$ and loadings of ex-ante returns $\boldsymbol{\Lambda}_{i}$ are identified as $\left(\rho_{i}, \boldsymbol{\Lambda}_{i}\right)=g^{-1}\left(\frac{\sigma_{u}^{2}}{\sigma_{\varepsilon}^{2}}, \mathbf{L}_{i}\right)$. The constant $\boldsymbol{\varphi}_{i}$ of the factor structure of ex-ante returns, and the cost of equity $\eta_{i t}$ then follow from the relationships of proposition 3 .

From this, the ex-ante beliefs about returns of firm $i$ 's are identified as:

$$
\widetilde{\mathbf{r}_{i t}}=\boldsymbol{\varphi}\left(\mu, \sigma_{\varepsilon}^{2}\right)+\boldsymbol{\Lambda}\left(\mu, \sigma_{\varepsilon}^{2}\right) \cdot \mathbf{f}_{i t}+\sigma_{\varepsilon}^{2} \boldsymbol{\epsilon}_{\boldsymbol{i t}},
$$

where $\boldsymbol{\epsilon}_{\boldsymbol{i t}}$ is a standardized residual and $\mathbf{f}_{i t}$ is the $J \times K$ matrix of factors. A convenient identification restriction for $\left(\mu, \sigma_{\varepsilon}^{2}\right)$ is to take the overall mean and residual variance $\sigma_{\varepsilon}^{2}$ of all assets to be equal to the historic residual variance in a factor decomposition of the ex-post $\mathbf{r}_{i t}$. The model identifies how both cross-sectional and panel differences in net demand reflect such variations in the ex-ante beliefs about returns.

\section{Data and Estimation Procedure}

The estimation of the model requires data on net demand in amount of currency units by firm and financial instrument, and first and second moment of ex-post returns.

We focus on the case of the French economy, and obtain sectoral accounts from Eurostat and Insee from 2000.1 to 2015.4. The Eurostat data provide information at quarterly frequency on amounts in Euro of stocks and changes due to valuation, flows and reclassifications by institutional sector and category of financial instrument. Quarterly time series on stocks and changes of the non-financial asset are imputed from annual data obtained from 
Insee (see Appendix B.2 for details). Sectoral accounts provide full coverage of sectoral balance-sheet and amounts outstanding by instrument, which is crucial to build funding constraints and market clearing conditions. Summarizing, we obtain complete balancesheet for six domestic sectors and the rest of the world account. The six domestic sectors are the following:

1. Banking (including the central bank) sector

2. Insurance sector

3. Mutual funds (including to a small extent also other financial institutions)

4. Corporate sector

5. Household (including non-profit institutions serving households) sector

6. and the Public sector.

Balance-sheets are broken down to one real asset and 19 categories of financial instruments including currency, deposits, securities (stocks, debt, fundshares), loans (short-term, longterm), entitlements (insurance, pension), and derivatives.

In order to obtain the first and second moment of returns, we construct time series of returns (i) due to valuation changes and (ii) due to payoffs. Returns due to valuation changes can be derived from information on the amount in Euro of stocks outstanding and valuation changes by financial instrument and sector. Returns due to payoffs on financial instruments are constructed from information recorded in the income accounts on different types of income received and paid by sector. Types of income are dividends, interest payments, investment income attributable to mutual fund shareholders, insurance policy holders, and investment income payable on pension entitlements. Since each type of income (for example interest payments) can stem from several financial instruments (for example interest payments on loans and coupons on debt securities), the attribution of income recorded at the sectoral level to instruments bearing a common type of income is not trivial. Appendix B.1 shows how the variation of balance-sheet positions and income received or payed across sector can be used for the estimation of returns.

We proceed as follows: First, we estimate a dynamic factor model for net demand with an autoregressive process of order one for the unobserved factors. Second, we use the inverse of the mapping between reduced form and structural parameter (see section 3.2) to 
find constant and loadings of the factor structure of ex-ante returns and the shadow value of the equity.

\section{Estimation Results, Financial Networks, and Propagation}

\subsection{Determinants of Net Asset Demands: Dynamic Factors and Macroe- conomic Variables}

The estimation of the dynamic factor model enables both the factors and the factor loadings to vary across institutional sectors. The estimation results reveal however that the factor are rather similar across sectors with some variation in their order of importance for explaining the variance of net demand. In order to interpret the factors, we run a series of bi-variate regressions in which each factor, estimated for each sector, is regressed against a number of macroeconomic variables capturing global and Euro Area specific macroeconomic conditions. The macroeconomic variables include financial variables such as interest rates and VIX, and real variables such as GDP growth and trade growth, for either the US, the World, or the Euro area. These variables are considered both in level and in first difference. Table 1 provides the sources of each variable.

Table 3 to Table 9 report, for each sector, the R-square explained by the four macroeconomic variables that have the highest explanatory power. The first line of each table reports the percentage of variance explained by each factor. The fraction of the variance

of the net demand explained by the first five factors ranges between 56 and 62 percent depending on the institutional sector. Figure 1 and Figure 2 plot for each sector the 20002015 quarterly time series of the first four factors along with the macroeconomic variable with the strongest explanatory power. Both factors and macro variables are normalized and smoothed by taking a moving average of order 4 in order to focus on comovement.

For the banking sector, the first factor captures elements of the global cycle (MirandaAgrippino \& Rey 2015) with a positive correlation with the first difference in one-year and two-year US interest rate, and a negative correlation with the VIX. As shown on Figure 1, panel (a), the change in the one-year US interest tracks extremely well the first factor, especially so during 2007-2008 crisis, and up to the point where the US falls into zero lower bound and the one-year interest rate becomes virtually unchanged. While the first factor captures the US crisis of 2007-2008, the second factor captures well the Euro Sovereign Debt crisis of 2011-2012. Indeed more than 70 percent of the variance of the second factor 
is explained by the change in the average interest rate of the GIIPS countries (Greece, Ireland, Italy, Portugal, Spain). Figure 1, panel (a) shows that indeed the second factor and the change in interest rate in GIIPS countries vary almost one to one throughout the period. Given the exposure of the French banking sector the Euro Sovereign Debt crisis in Southern Europe, it is very reassuring to see it captured by the second factor.

The third factor captures the US and Europe Monetary Policy stances as measured by the shadow rate computed by Wu \& Xia (2016) and designed to capture macroeconomic impact of monetary policy at the zero lower bound. The fourth factor is negatively correlated with long-term interest rates in both the US and Euro area, and captures the secular decline in the long run interest rate over the period, an obvious concern for the profitability of banks.

For the insurance sector (Table 1, panel b) the first factor explaining the net asset demand is strongly correlated with long-term interest rate in the US and in Europe. This feature is consistent with insurance funds being massively invested in long-term safe fixedincome securities. The change in the VIX is negatively related with the second factor and explains 36 percent of the variance of net asset demand. The change in the VIX tracks indeed well the long swings in the second factor. The other three factors correlate mostly with the ECB policy rate, the change in short-term US interest rate, and the change in the GIPS interest rates.

For the mutual funds sector (Table 1, panel c) the first factor displays its higher correlation with the VIX, the second factor with the level of the short US interest rate with, and the third fact with the change in short-run US interest rate. All three factors are related to the global cycle which is consistent with many of the mutual funds allocating asset globally, and thus being especially sensitive to global risk. The last two factors are related to the Euro cycle with factor 4 being correlated with Euro area long-term interest rate, and factor 5 with the Euro area policy rate.

While real global and Euro area specific real variables (GDP growth, trade growth) do not play a major role for the three financial sectors, they do matter for the corporate sector (Table 2, panel a). The first factor displays a high correlation (0.58) with the change in advanced economy interest rate but also a high correlation (ranging from 0.49 to 0.55 ) with world trade growth and world GDP growth. The first factor captures therefore both the financial and the real dimension of the Global Cycle. The second factor correlates highly (0.5) with the Euro area growth rate, and the three others with interest rate conditions in the US, the Euro Zone, and the GIIPS countries. 
For the household sector (Table 2, panel b) the first two factors also correlate strongly with the global financial and real cycle. The first factor displays a high correlation (0.49) with the change in the US policy rate, and the second factor displays a strong correlation with both the real GDP World growth (0.48), and with the VIX (0.61). To interpret those result, one shall bear in mind that we are computing the determinant of the net asset demand (assets minus liabilities) and so a fair share of these results do correspond with the household credit crunch experienced by households in the wake of the 2007-2008 crisis. The three other factors capture a mix of interest rate conditions in the US, the Euro area and the GIIPS, global liquidity, and Euro area export growth.

For the public sector (Table 2, panel c), the first factor correlates strongly positively with the VIX index (0.49), and the second sector correlates strongly positively with real word growth. The public sector asset positions are very small compare to its liability position and therefore these factors explain mostly public sector debt, and its countercyclical nature. Finally the rest of the world net demand is explained by factors reflecting interest rate conditions in the US, the Euro area, and the GIIPS countries (Table 2, panel c). The first factor, which captures well the 2007-2008 crisis, corresponds to the global cycle, and correlates strongly with the US policy rate. The second factor and third factor capture the Euro sovereign rate crisis and thus correlates strongly with interest rate in the GIIPS countries. The last two factors capture the US medium to long run interest rate, and the ECB and Fed policy rates, respectively.

Overall it is very reassuring to observe that factors explaining net asset demand display a time series profile which capture well either the 2007-2008 financial crisis or the 2011-2013 Eurozone sovereign crisis, and correlate well with the financial or real variables capturing the global cycle, the Euro cycle, and sovereign stress in the GIIPS countries.

\subsection{Structural Estimation Results}

The procedure described in section 4 enables to estimate the structural parameters of the model: risk-aversion, beliefs about future returns, and the shadow value of equity.

\section{Risk-aversion}

As discussed in section 3.2, the mapping between the factor structure of net demand and that of the return beliefs identify $\rho \sigma_{\varepsilon}^{2}$, that is the degree of risk-aversion multiplied by the residual variance of the belief return model. One way to recover the degree of risk-aversion 
is by matching the overall variance of return beliefs to the variance of ex-post returns. Table 2, upper panel, report risk-aversion estimates, one by sector, obtained by matching variances. This approach generates estimates, which tend to be on the high side, ranging from 8.9 to 21.7, depending on the institutional sector, but which are not uncommon in the finance literature. ${ }^{6}$ The ordering of risk-aversion between sectors is sensible with a higher estimated risk-aversion in financial sectors subject to capital requirement (banks, insurance) than for the mutual funds sector or the corporate sector.

While imposing the matching of belief returns to ex-post returns is a way to discipline belief formation, one cannot rule out that beliefs are substantially more volatile than ex-post returns. Moreover by letting the variance of return beliefs to be a multiple of the variance of ex-post returns (Table 2, bottom three panels), we estimate risk-aversion parameters that are substantially smaller. The estimation of return beliefs presented in the next section are obtained by matching the variance of return beliefs with that of ex-post returns. ${ }^{7}$

\section{Return Beliefs}

The estimated factor model for return beliefs, described in Section 3.1, yields for each sector and each instrument, a one-quarter-ahead return forecast. Figure 3 and Figure 5 plot alongside the time series of realized ex-post returns the time series of corresponding return beliefs, the 95th percent confidence forecast interval band, for the financial sectors and the real sectors, and for each of the following financial instruments: Bonds (ShortTerm and Long-Term), Stocks (Listed and Unlisted), Mutual Fund Shares (Money Market and Non-Money Market). The R-square of an OLS regression of ex-post returns on ex-ante return beliefs and a constant is reported on the right-hand upper corner of each plot.

In many cases, the ex-ante return beliefs predict well ex-post returns. The corporate sector ex-ante return beliefs explain 31 percent of the variance of ex-post stock returns. The household sector ex-ante return beliefs explain 35 percent of the variance of the Non Money Market Mutual Funds ex-post returns. In both cases, the time series of return belief tracks very well the asset crash of 2007-2008, and the subsequent rebound. Other good predicting performance include the prediction of unlisted stock returns by the banking sector and the household sector, the prediction of short-term bonds return by the insurance sector, the

\footnotetext{
${ }^{6}$ Ang (2014) and Ait Sahalia \& Lo (2000)

${ }^{7}$ Estimations based on alternative calibration of risk-aversion are available from the authors.
} 
prediction of the return to mutual funds by the corporate sector, the household sector, and the mutual fund sector itself.

In several instances however, the model either does not predict ex-post return or more puzzlingly its predictions negatively correlate with ex-post returns. We shall notice that this feature is mostly driven by the 2007-2008 crisis. A potential explanation is that several institutional sectors during that period had to increase their purchases of assets even if their returns were declining. Since beliefs are implicitly derived from net demands, those counter-cyclical purchases can drive the negative correlation between return beliefs and ex-post returns. This is the case for the banking sector which hoarded short term liquid assets during the crisis, for the public sector who bought large stock shares to recaptilize the banking sector and the automobile sector during the crisis, and for the insurance sector which increased considerably its asset holdings during the crisis (Heipertz et al. 2016).

Figure 4 and 6 illustrate the dispersion of beliefs between the three financial sectors (banking, insurance, mutual funds), and between the three real domestic sectors (corporate, household, public). Overall, while there is substantial disagreement in beliefs at each point in time, the return beliefs of the banking sector and the mutual fund sectors display a strong comovement. The correlation between the return beliefs of the banking sector and those of the mutual fund sectors are high for most financial instruments: listed stocks (0.54), unlisted stocks (0.46), non money-market mutual fund share (0.34), short-term debt (0.40). There are however episodes in which the return beliefs differ substantially. For example, the mutual fund sector exhibited much more pessimistic beliefs during the 2007-2008 crisis about the return to stocks and to debt securities, while the banking sector became more pessimist on the returns to stocks and mutual fund shares during the sovereign crisis of 2011-2012. One interpretation is that the bank bailout of 2007-2008 avoided the need for banks to engage in massive fire-sales (with deep discount prices), while the mutual fund sector faced large withdrawals from customers and had to engage in such fire-sales. On the opposite, banks were suffering from significant liquidity or solvency stress during the sovereign debt crisis, due to their exposure to GIIPS debt, and therefore faced a pressure to sell-off rapidly other assets that the mutual fund sector did not experience then.

The comparison of beliefs among the three real sectors reveal a sharp contrast between the belief returns of the corporate and household that typically comove, and that of the public sector that often displays counter-cyclical beliefs, and especially so during the 20072008 crisis. This is consistent with the role played by government in providing bailout and in the debt financing of large public sector deficits during the crisis. 


\section{Value of Equity}

Figure 7 plots the shadow value of equity for each of the sector of the economy. For the corporate and banking sector, the shadow value of issuing more equity declined during the crisis and rebounded afterwards. The insurance sector value of equity increased sharply in the aftermath of the crisis in line with its increase in net asset holdings. The public sector value of equity declined sharply in the crisis and post-crisis period, a period during which public debt increased strongly.

\subsection{Networks, and Shock Propagation}

Following section 2.4, the estimated net asset demand model yields both a network of assets and a network of institutions. We focus here on the network formed by the tradable instruments: Bonds (Short-Term and Long-Term), Stocks (Listed and Unlisted), Mutual Fund Shares (Money Market and Non-Money Market). Figure 8 represents the network of financial instruments for two dates: (i) the first quarter of 2008, that is before the financial crisis; (2) the recent period (2015.Q1). In the pre-crisis era, the demand for equity and non money-market mutual fund share were the most affected by changes in the returns to other assets. By contrast, in the post-crisis era, the demand for long-term debt became the most affected demand, reflecting both increased issuances of corporate debt in a low-interest rate environment, and increased loading of government securities in balance-sheets, and especially so in the banking and insurance sector.

A convenient way to illustrate the importance of network propagation is to contrast the partial equilibrium effect of a shock, which by construction abstracts from any networks effects, to the general equilibrium effect which incorporates the full array of network effects . In order to do this comparison, we fist derive the partial equilibrium effect of a shock to the equity of sector $k$.

Proposition 4. The partial equilibrium effect of a shock to sector $k$ 's equity $E_{k t}$ on net demands is given by

$$
\frac{\partial \boldsymbol{\Delta}_{k t}}{\partial E_{k t}}=\Sigma_{k}^{-1}\left(\mathbf{1}^{\prime} \Sigma_{k}^{-1} \mathbf{1}\right)^{-1} \mathbf{1}, \quad \text { and } \quad \frac{\partial \boldsymbol{\Delta}_{k^{\prime} t}}{\partial E_{k t}}=\mathbf{0} \quad \forall k^{\prime} \neq k
$$

where $\Sigma_{k}$ is the $J \times J$ variance-covariance matrix of return beliefs of sector $k$. The partial equilibrium effect of equity on net demand is time independent. 
Note that while the partial equilibrium impact of a shock on equity is constant, the general equilibrium effect varies over time along with the price sensitivity of net demands to changes in log returns which characterize the time-varying network of financial instruments (see section 2.4).

Table 10 shows the partial and general equilibrium effect of a shock to the equity of the banking sector. The shock corresponds to one unit increase in the capital base of the banking sector. Table 10, panel (b) shows the effects for 2015.Q1, a period of tranquil times and Table 10, panel (a) for 2008.Q4, a period of crisis time.

By comparing the first and second column of table 10, panel (b), we can contrast the partial and general equilibrium effects of the shock the banking sector itself. In the partial equilibrium effect the one-unit increase in equity finance a one-unit increase in net assets distributed more of less equally across the three asset classes (stocks, bonds, mutual funds). In general equilibrium however price effects reduces the increase in net asset demand for all asset classes and the total net demand for assets in the banking sector ends up being 30 percent smaller than in partial equilibrium.

For the other sectors, only the general equilibrium effects arise and they appear to be very heterogeneous across sectors. Following a one-unit shock to equity in the banking sector, the corporate sector also increase its net asset demands $(+0.58)$ but all the other sectors experience a decrease in net asset demand. The reduction is small for the household sector (-0.045) but with substantial rebalancing in net asset position away from listed stocks, short-debt debt, and non money market mutual funds, and towards unlisted stocks, long-term debt, and money market funds. The reduction in net asset demand is much larger for the insurance sector with a reduction of -0.45 in total net asset demand and a reduction in the net asset demand for all asset classes.

The re-balancing of net demand between the banking sector and the insurance sector is quiet remarkable as it is closely related with what happened in the aftermath 2007-2008, that is a retrenchment of the banking sector net asset holdings following severe capital losses, and an expansion of the insurance sector net asset holdings(Heipertz et al. 2016). The last column displays the change in log returns and indicates a marked dispersion in returns between assets with a decline in the returns of listed stocks, short-term debt, and non money-market mutual fund shares while the returns of other instruments increased.

Table 10, panel (a) explores network effects that unfolded in the midst of the 2007-2008 financial crisis (2008.Q4). The increase in net asset demand by the banking and corporate sectors was, back then, considerably lower (0.5 and 0.215) than in "tranquil times". By 
contrast, all other sectors experienced a decline in their net asset demand. That decline was more marked than in "tranquil times" for households (-0.08), but less so for the insurance sector (-0.26). Meanwhile, the Rest of the World increased net asset holdings relative to "tranquil times".

Overall, it turns out that the network effects derived from the general equilibrium analysis are (i) sizeable in some sectors, of a magnitude comparable to the sector where the shock originated; (ii) very contrasted across sector, vindicating the phenomonon of large net demand shifts across sectors such as between the banking and the insurance sector.

\section{Conclusion}

This paper develops a novel methodology to estimate the key parameters of a general equilibrium model of net asset trade by using the factor structure of net asset demand. The structure of net asset demand is well explained by a number of factors that strongly correlate with macro-variables capturing the global cycle or the Eurozone cycle. The estimated model for return beliefs predicts well ex-post returns for many sectors and many financial instruments. The cased of predictions failure can be related to special episodes such as the 2007-2008 crisis during which some sectors (insurance, public sector) displayed a counter-cyclical behavior increasing net holdings of assets whose return were declining. The estimated model yields both a network of financial instrument and a networks of institutions. The transmission of shocks in the networks, through price externalities, reveal network effects which are large and strongly heterogeneous across sectors. Extending the model to account for regulatory constraints in order to simulate regulatory changes, and re-estimating the model on individual institutions are the next steps on the agenda. 


\section{References}

Acemoglu, D., Ozdaglar, A. \& Tahbaz-Salehi, A. (2015), 'Systemic risk and stability in financial networks', American Economic Review 105.

Ait Sahalia, Y. \& Lo, A. W. (2000), 'Nonparametric risk management and implied risk aversion', Journal of Econometrics 94.

Ang, A. (2014), 'Asset management: A systematic approach to factor investing', OUP Catalogue, Oxford University Press .

Berrada, T. (2006), 'Incomplete information, heterogeneity and asset pricing', Journal of Financial Econometrics 4.

Eisenberg, L. \& Noe, T. H. (2001), 'Systemic risk in financial systems', Management Science 47.

Elliott, M., Golub, B. \& Jackson, M. O. (2014), ‘Financial networks and contagion', American Economic Review 104.

Gandhi, A. \& Serrano-Padial, R. (2015), 'Does belief heterogeneity explain asset prices: The case of the longshot bias', Review of Economic Studies $\mathbf{8 2}$.

Goyal, S. \& Vega-Redondo, F. (2005), 'Network formation and social coordination', Games and Economic Behavior 50.

Greenwood, R., Landier, A. \& Thesmar, D. (2015), 'Vulnerable banks', Journal of Financial Economics 115.

Heipertz, J., Ranciere, R. \& Valla, N. (2016), 'Domestic and international sectoral portfolios: Network structure and balance sheet effects', mimeo .

Jackson, M. \& Watts, A. (2002), 'The evolution of social and economic networks', Journal of Economic Theory 106.

Koijen, R. S. \& Yogo, M. (2016), 'An equilibrium model of institutional demand and asset prices', NBER Working Paper No. 21749.

Mas-Colell, A., Whinston, M. D., Green, J. R. et al. (1995), Microeconomic theory, Vol. 1, Oxford university press New York. 
Miranda-Agrippino, S. \& Rey, H. (2015), 'World asset markets and the global financial cycle', NBER Working Paper No. 21722.

Wu, J. C. \& Xia, F. D. (2016), 'Measuring the macroeconomic impact of monetary policy at the zero lower bound', Journal of Money, Credit and Banking 48. 
Figure 1: Financial Sectors - Factors (black) and Macro-Variables (blue)

(a) Banking

Factor 1

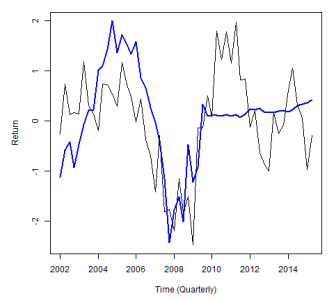

FD Yield 1y US

Factor 2

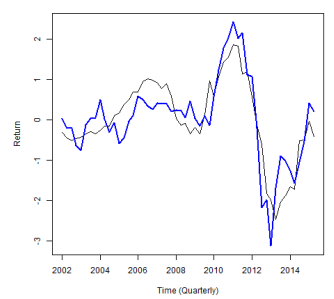

FD Int. Rate GIIPS

Factor 3

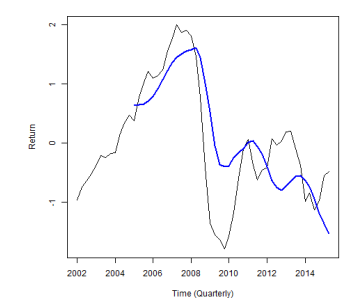

Shadow Rate ECB

Factor 4 (b) Insurance

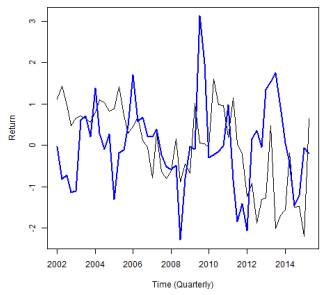

Yield 30y US

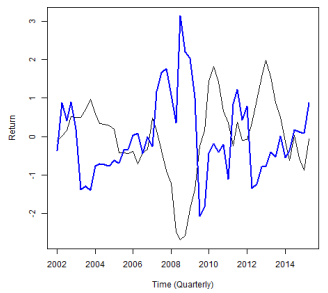

Growth Rate VIX

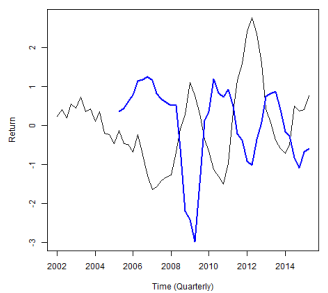

FD Shadow Rate $E C B$

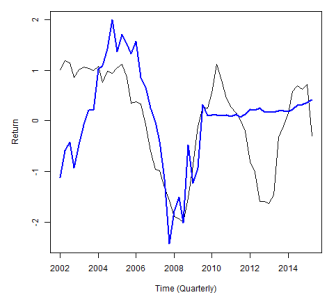

FD Yield 1y US (c) Mutual Funds

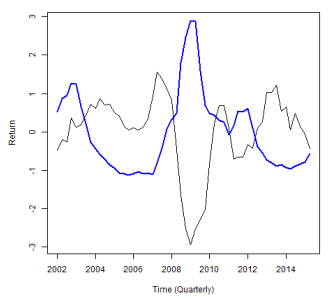

$V I X$

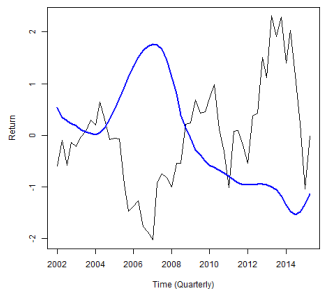

Yield 1y US

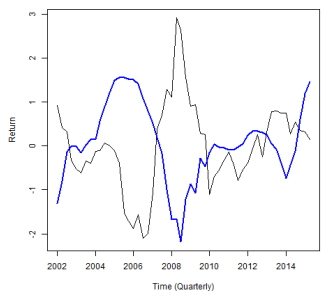

FD Shadow Rate FED

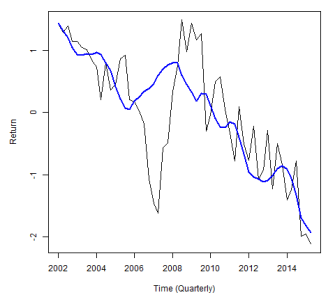

Yield 30y Euro 
Figure 2: Non-Financial Sectors and RoW - Factors (black) and Macro-Variables (blue)

(a) Corporate

(b) Household

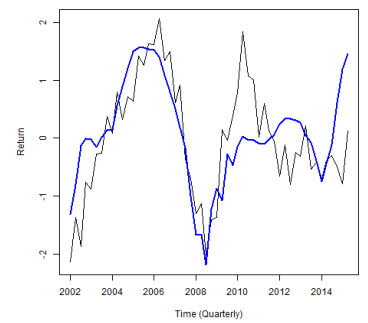

FD Shadow Rate FED

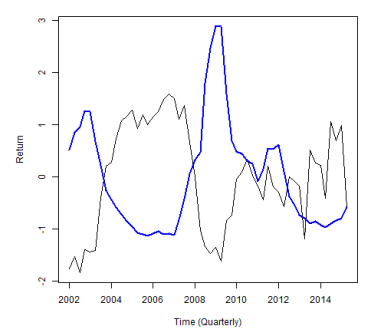

VIX

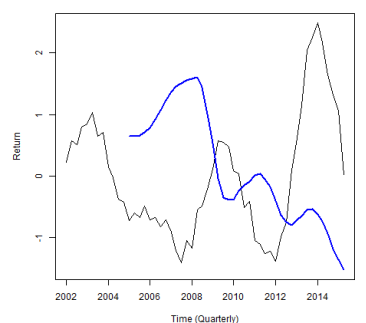

Shadow Rate ECB

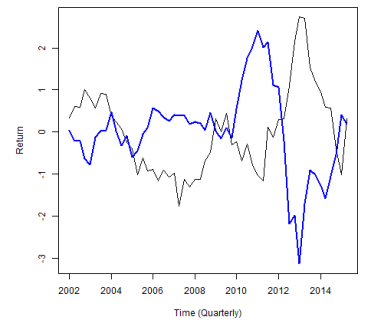

FD Interest Rate GIIPS

(c) Public

(d) RoW

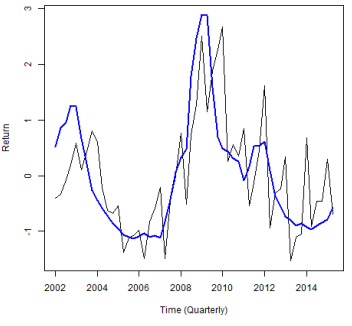

$V I X$

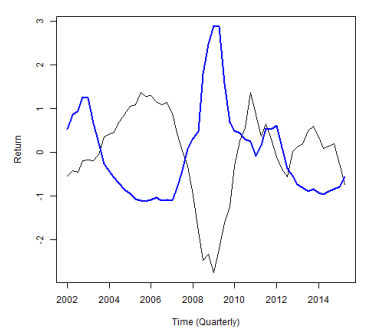

$V I X$

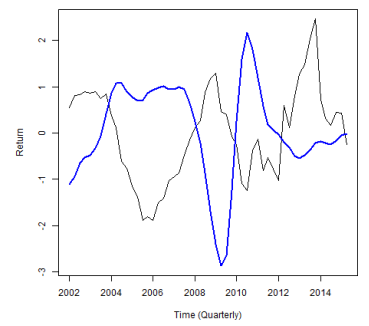

Real Growth Rate World

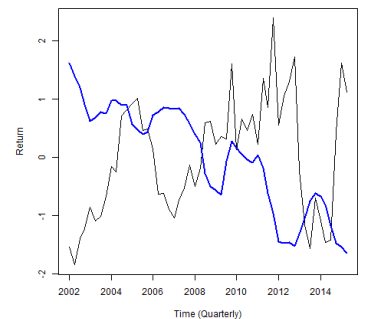

Yield 30y US

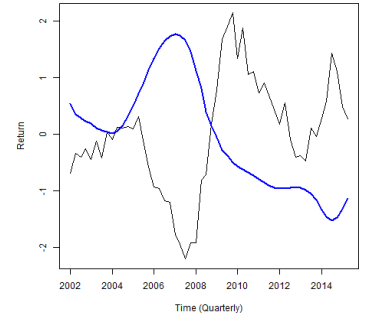

Shadow Rate FED

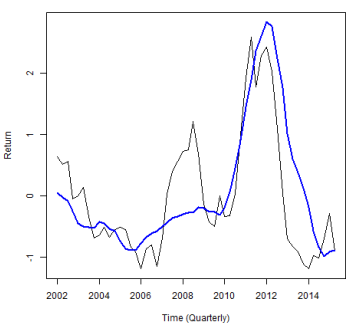

Interest Rate GIIPS

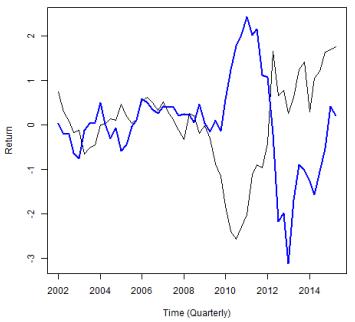

FD Interest Rate GIIPS

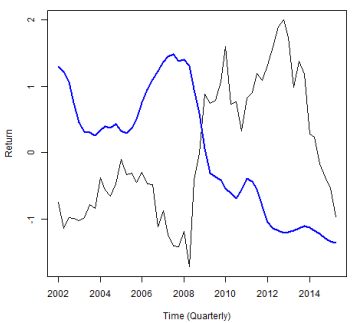

Yield 2y US 
Figure 3: Financial Sectors - Mean Beliefs (blue) with 95\% confidence bands versus Ex-Post Returns (black)

Banking
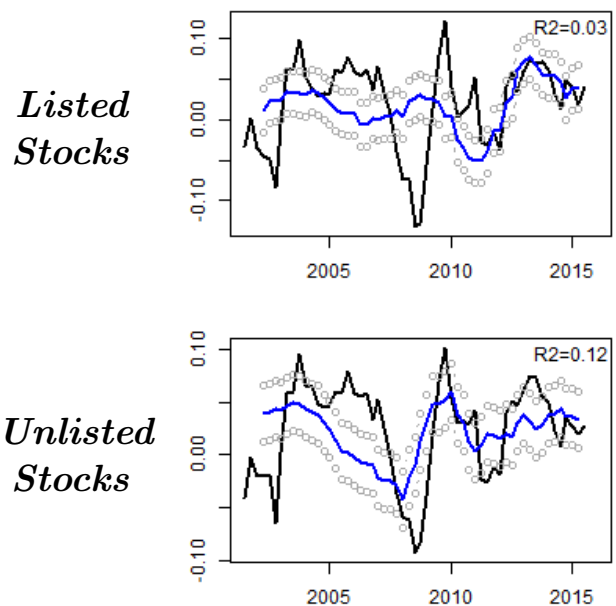

Unlisted Stocks
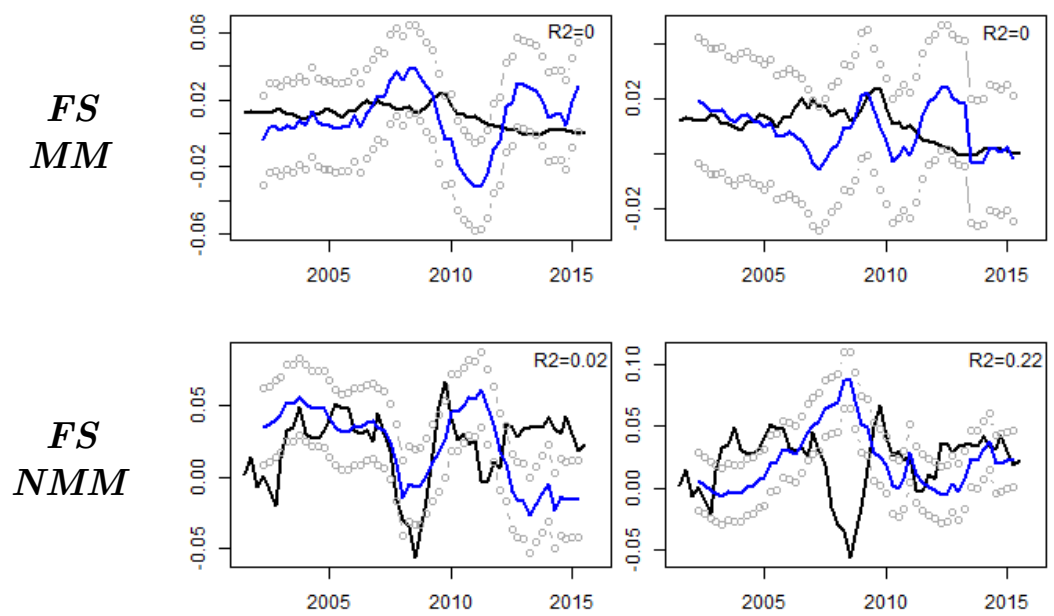

Insurance
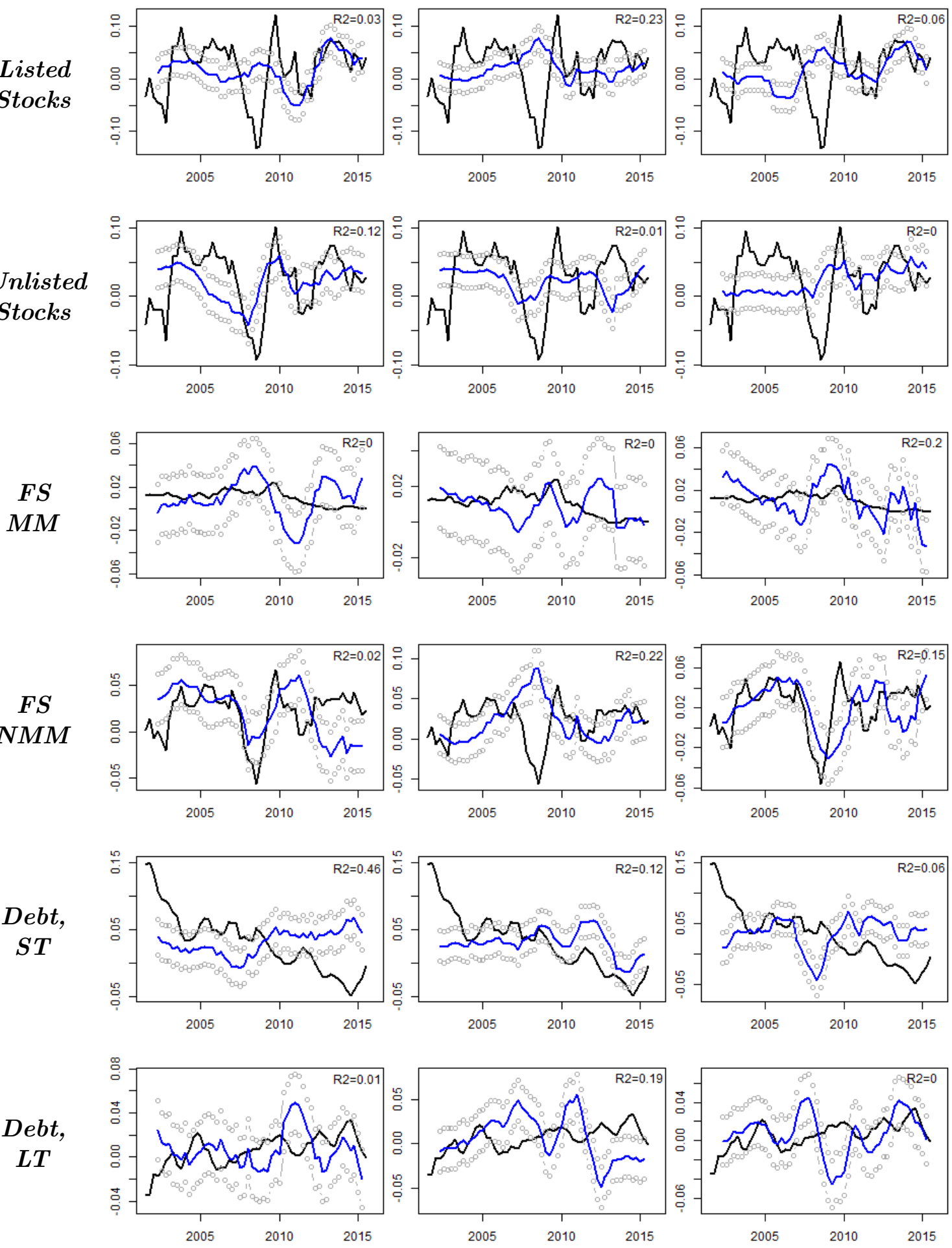
Figure 4: Financial Sectors - Beliefs Heterogeneity (blue=Banking, green=Insurance, red=Mutual Funds)

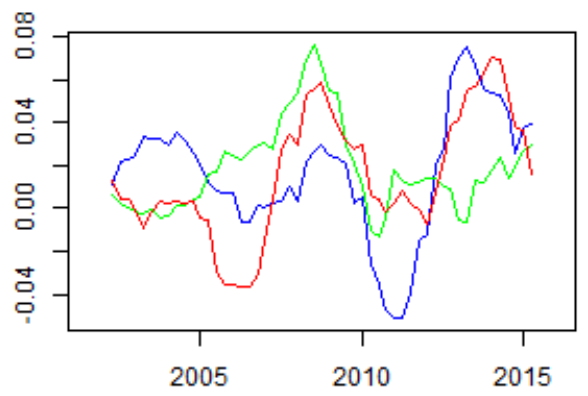

(a) Stocks, listed

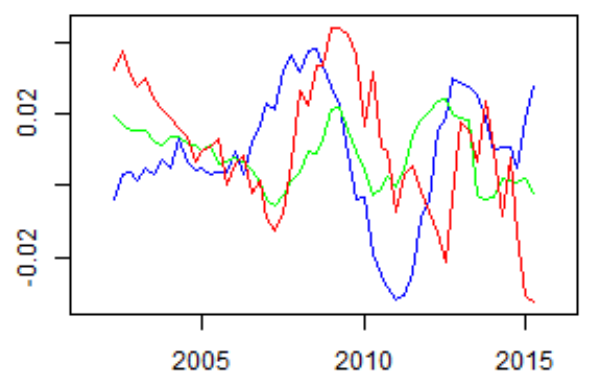

(c) Fundshares, Money Market

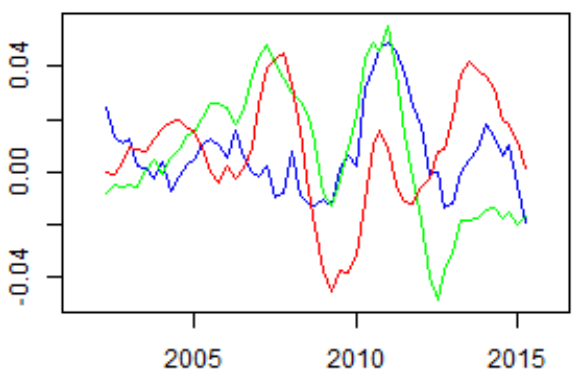

(e) Debt, $L T$

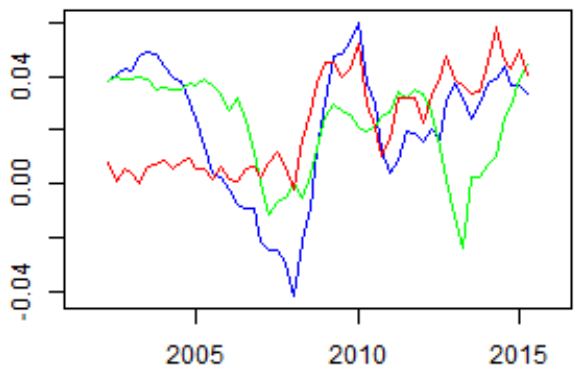

(b) Stocks, unlisted

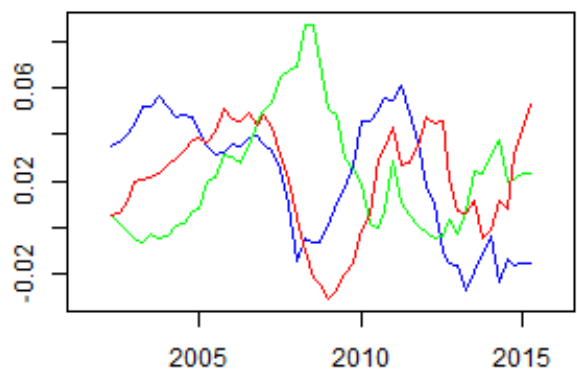

(d) Fundshares, Non-MM

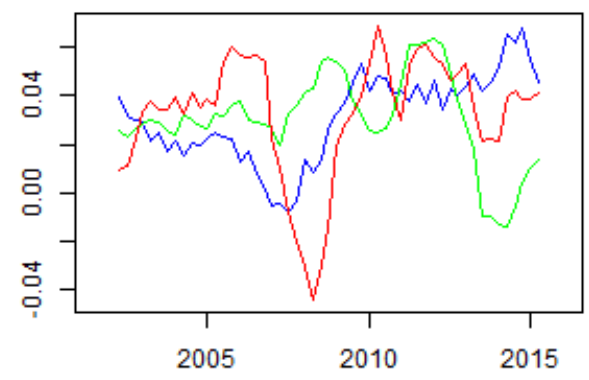

(f) Debt, ST 
Figure 5: Non-Financial Sectors - Mean Beliefs (blue) with 95\% confidence bands versus Ex-Post Returns (black)

Corporate
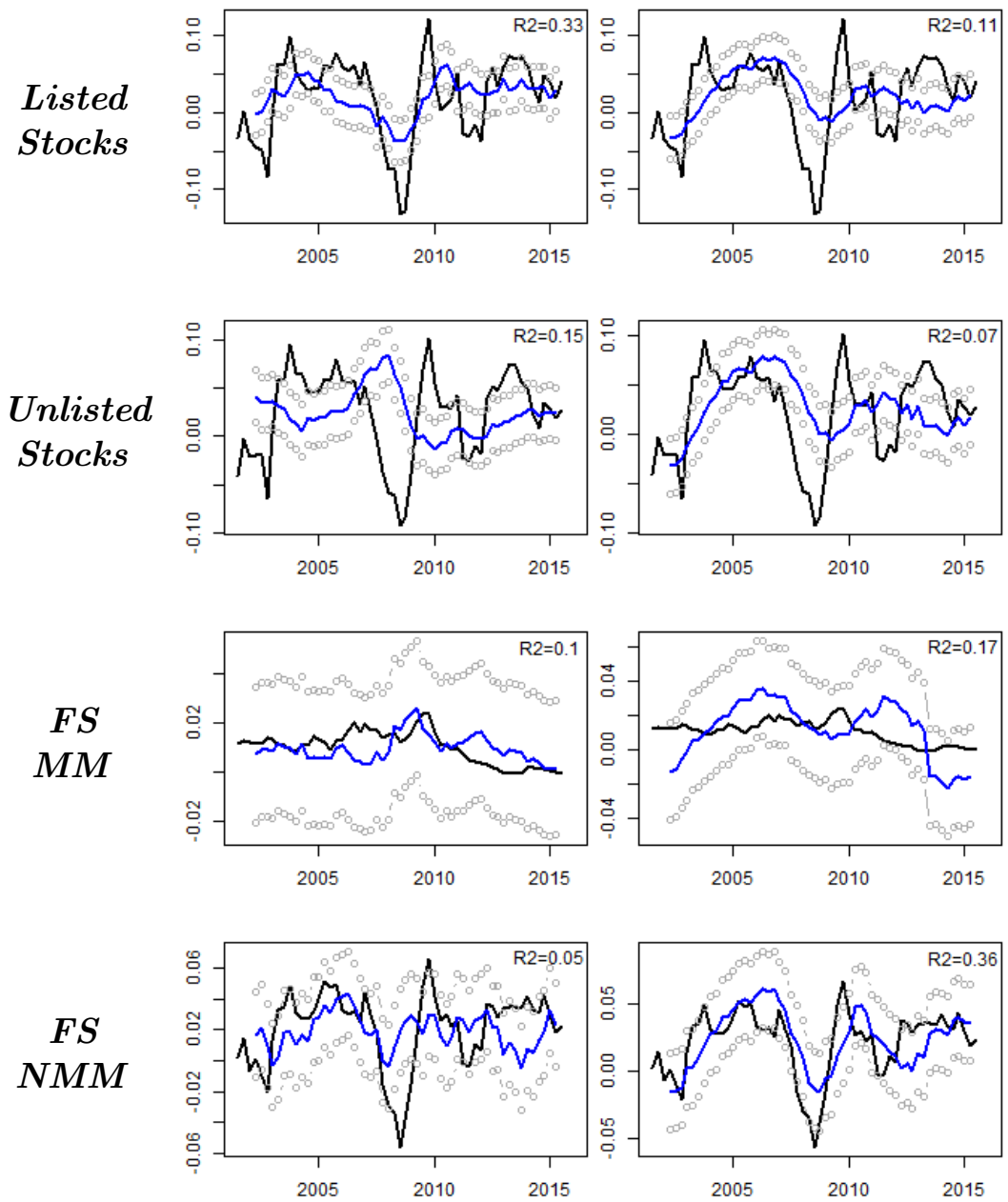

Household
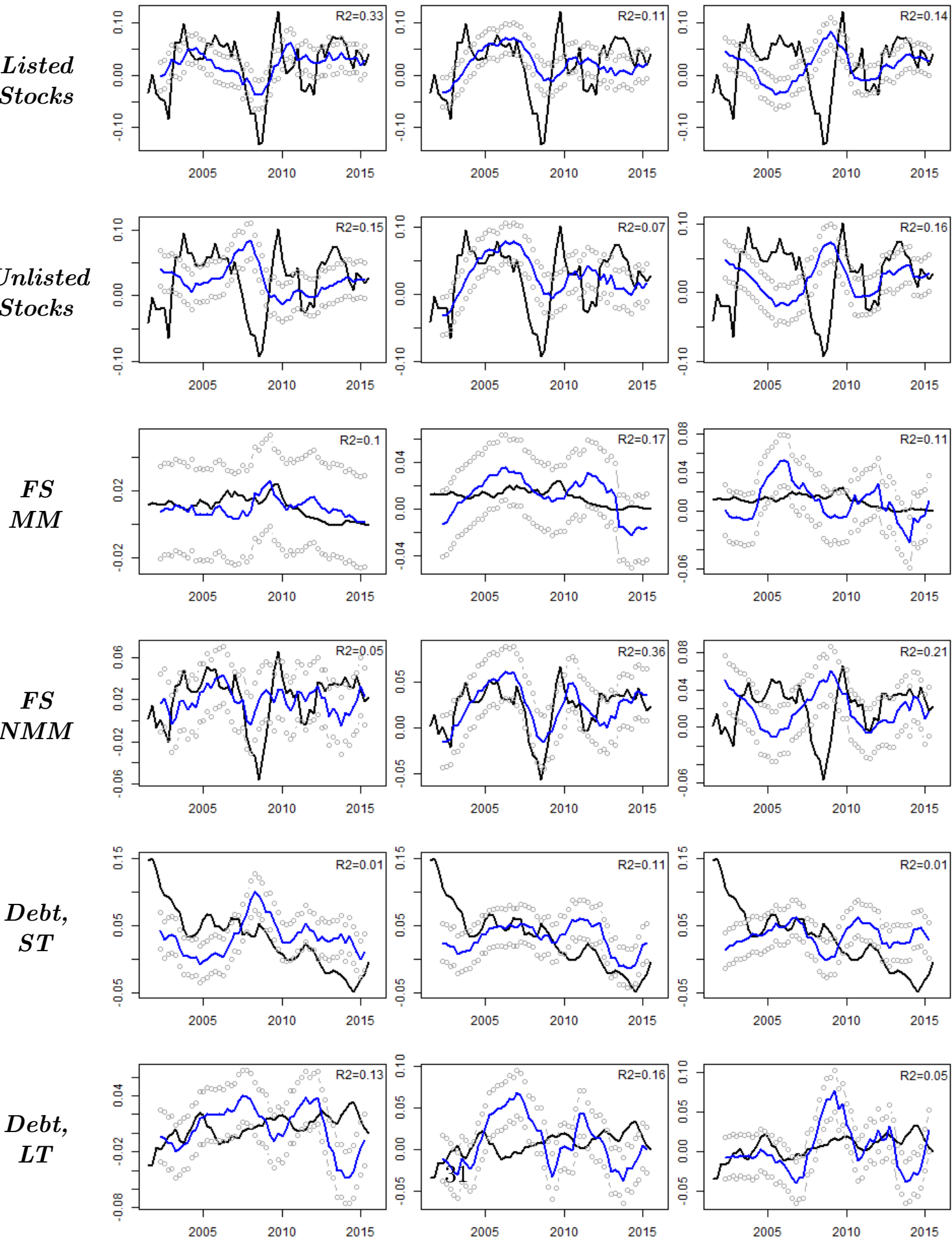
Figure 6: Non-Financial Sectors - Beliefs Heterogeneity (blue=Corporate, green $=$ Household, red=Public)

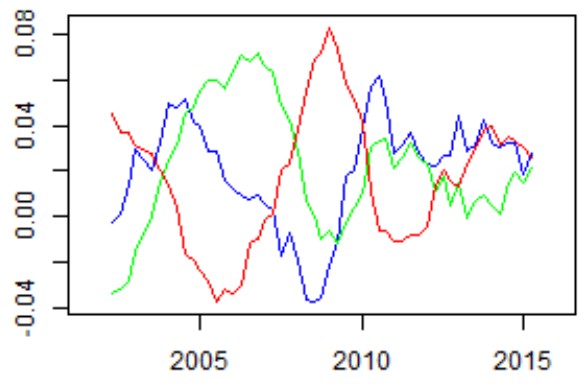

(a) Stocks, listed

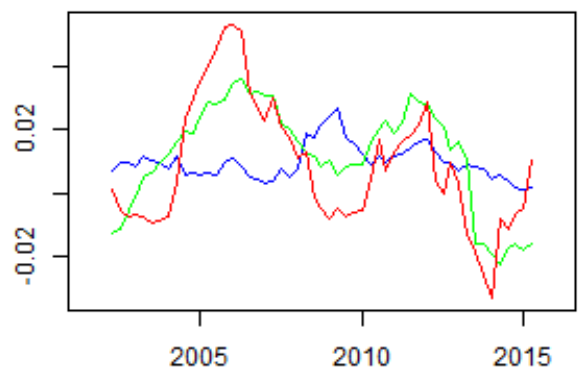

(c) Fundshares, Money Market

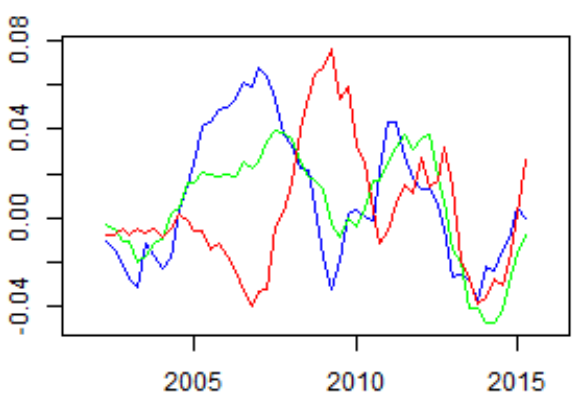

(e) Debt, $\boldsymbol{L T}$

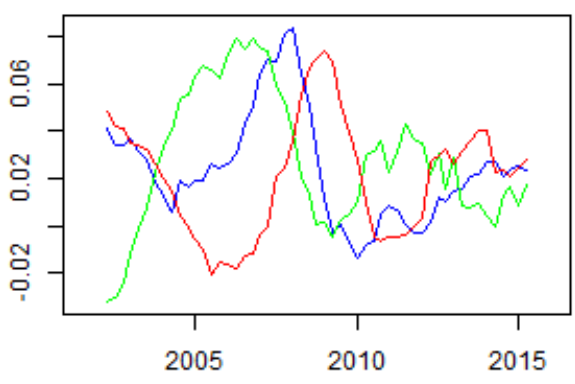

(b) Stocks, unlisted

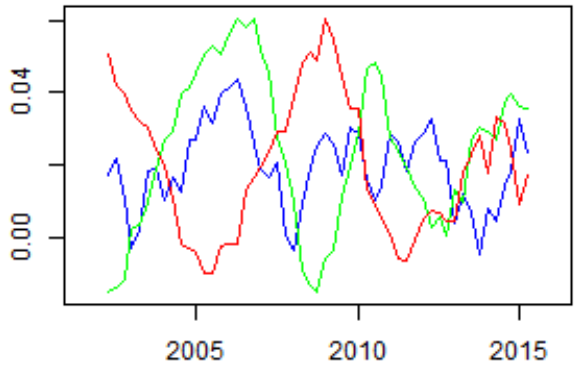

(d) Fundshares, Non-MM

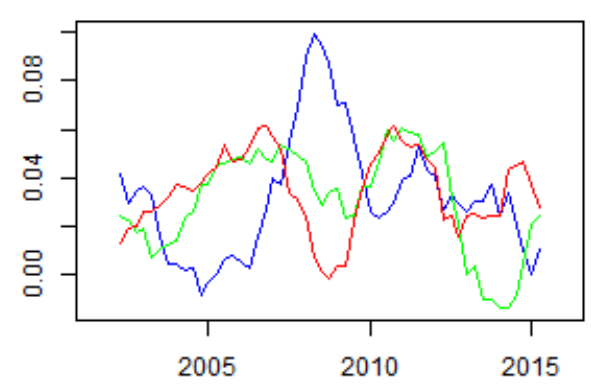

(f) Debt, $S T$ 
Figure 7: Cost of Equity

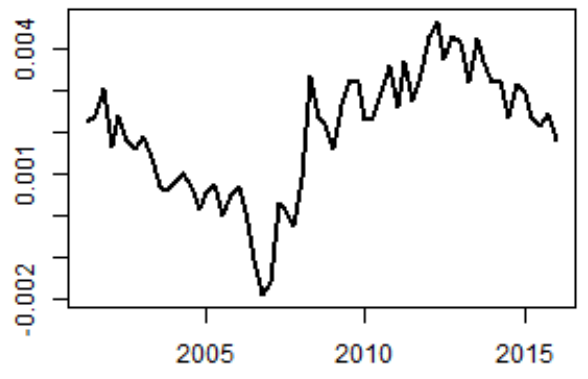

(a) Banking

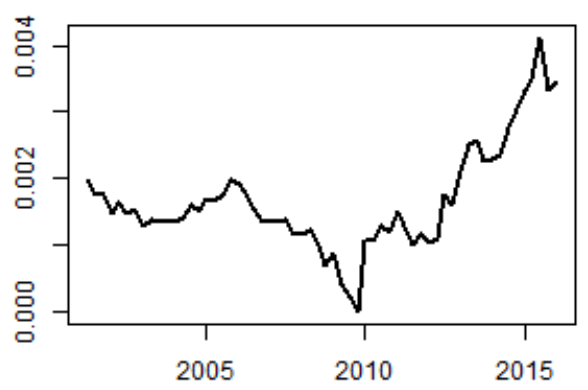

(c) Insurance

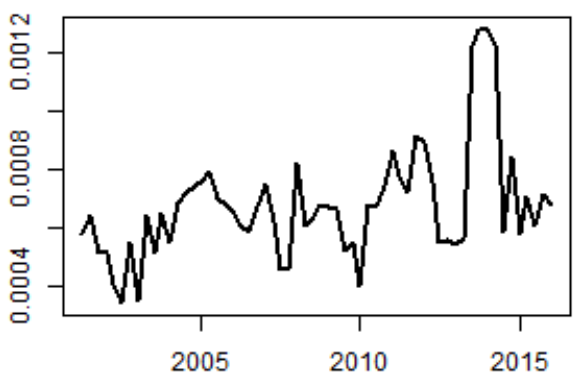

(e) Other FI

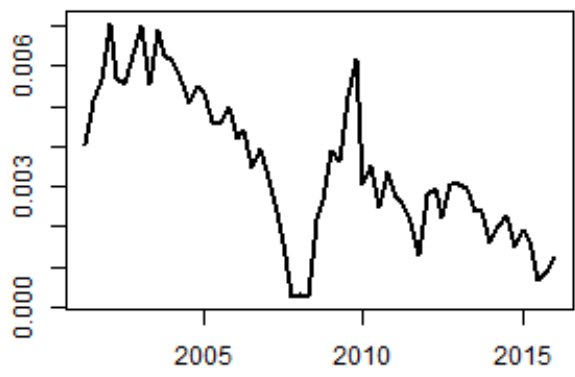

(b) Corporate

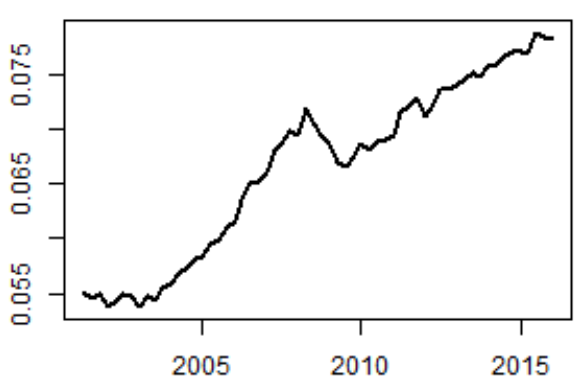

(d) Household

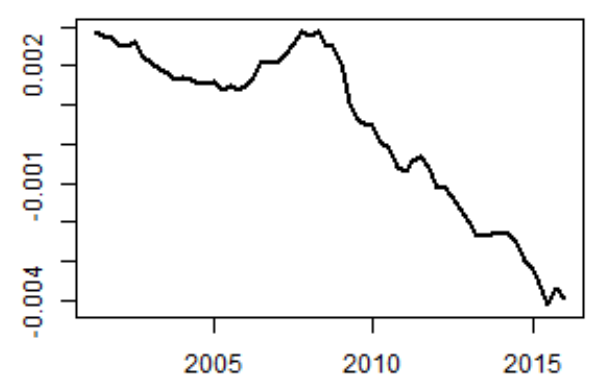

(f) Public 
Figure 8: Representation of the Network of Financial Instruments - Adjacency Matrix

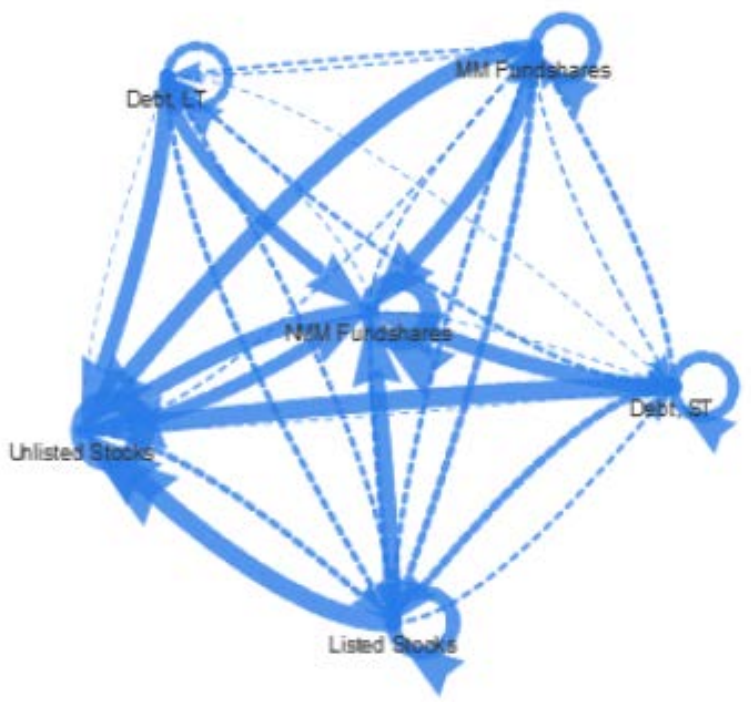

(a) $2008-Q 1$

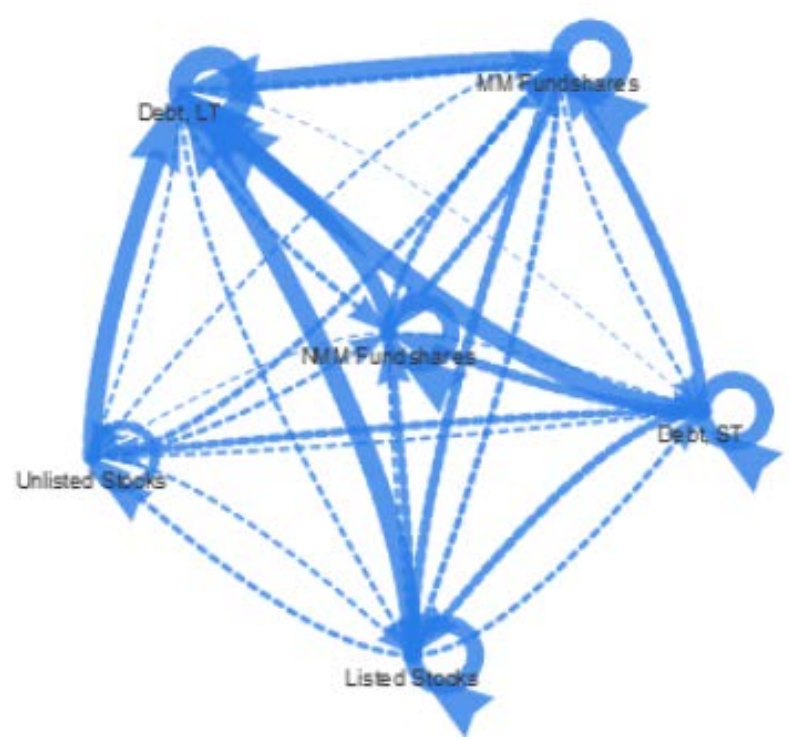

(b) 2015-Q1 
Table 1: Macro-Variables and Sources

\begin{tabular}{|c|c|c|}
\hline Macro-Variable & Source & Comments \\
\hline ECB and FED Shadow Rate & Wu and Xia (2016) & \\
\hline Interest Rate Adv. Economies & IFS & $\begin{array}{l}\text { Average of yields on government } \\
\text { securities of Belgium, France, } \\
\text { Netherlands, Germany, Italy, Japan and } \\
\text { the US }\end{array}$ \\
\hline Interest Rate GIIPS & IFS & $\begin{array}{l}\text { Average of Yields on government } \\
\text { securities of Greece, Ireland, Italy, } \\
\text { Portugal and Spain (GIIPS) }\end{array}$ \\
\hline Liquidity Growth World & IFS & $\begin{array}{l}\text { Q-on-q growth rate of the sum of } \\
\text { monetary aggregates M } 2 \text { of the Euro } \\
\text { area, Japan, the United Kingdom and } \\
\text { the US }\end{array}$ \\
\hline S\&P 500 VIX & $\mathrm{CBOE}$ & $\begin{array}{l}\text { Implied volatility of S\&P } 500 \text { index } \\
\text { options }\end{array}$ \\
\hline Real Export Growth Euro area & IFS & \\
\hline Real Export Growth World & IFS & \\
\hline Real GDP Growth Euro area & IFS & \\
\hline Real GDP Growth World & IFS & \\
\hline Real Import Growth World & IFS & \\
\hline Real Trade Growth World & IFS & \\
\hline Yield Cuve US & JP Morgan & Mid yield curve \\
\hline Yields Cuve Euro area & JP Morgan & Mid yield curve Germany \\
\hline
\end{tabular}


Table 2: Risk Aversion and Return Belief Uncertainty

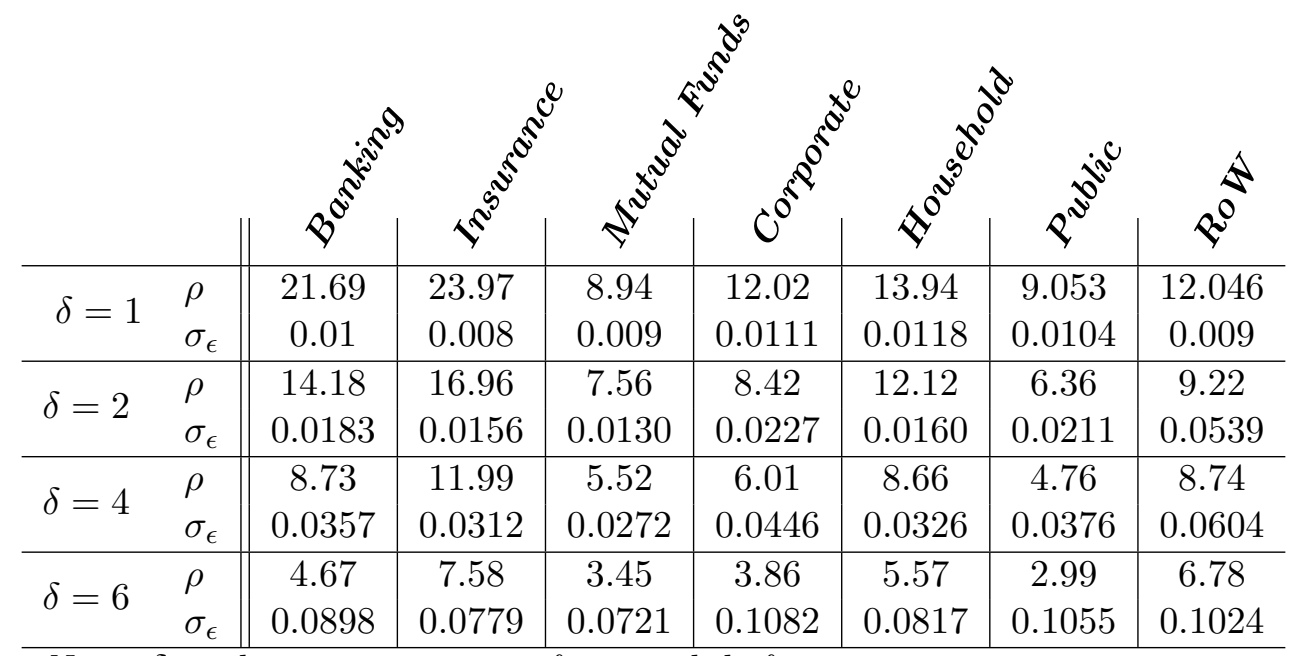

Note: $\delta$ is the variance ratio of return beliefs over ex-post returns. 
Table 3: Banking - Factors and Macro-Variables

\begin{tabular}{|c|c|c|c|c|c|c|c|c|c|c|}
\hline & \multicolumn{2}{|c|}{ Factor 1} & \multicolumn{2}{|c|}{ Factor 2} & \multicolumn{2}{|c|}{ Factor 3} & \multicolumn{2}{|c|}{ Factor 4} & \multicolumn{2}{|c|}{ Factor 5} \\
\hline Explained Variance & 0.19 & & 0.31 & & 0.41 & & 0.49 & & 0.57 & \\
\hline Observable & beta & $R^{2}$ & beta & $R^{2}$ & beta & $R^{2}$ & beta & $R^{2}$ & beta & $R^{2}$ \\
\hline first.diff.yield.1y.us & $0.58^{*}$ & 0.29 & & & & & & & & \\
\hline first.diff.yield.2y.us & $0.55^{*}$ & 0.22 & & & & & & & & \\
\hline growth.rate.vix & $-1.25^{*}$ & 0.21 & & & & & & & & \\
\hline interest.rate.advanced & $-0.17^{*}$ & 0.18 & & & & & & & & \\
\hline first.diff.interest.rate.gips & & & $1.09^{*}$ & 0.72 & & & & & $-0.25^{*}$ & 0.15 \\
\hline real.growth.rate.world & & & $0.19^{*}$ & 0.21 & & & & & & \\
\hline first.diff.interest.rate.advanced & & & $1.88^{*}$ & 0.19 & & & & & & \\
\hline real.export.growth.world & & & $0.04^{*}$ & 0.18 & & & & & & \\
\hline yield.1y.us & & & & & $0.31^{*}$ & 0.61 & & & & \\
\hline shadow.rate.ecb & & & & & $0.3^{*}$ & 0.56 & & & & \\
\hline shadow.rate.fed & & & & & $0.2^{*}$ & 0.55 & & & & \\
\hline yield.2y.us & & & & & $0.31^{*}$ & 0.51 & & & & \\
\hline yield.30y.us & & & & & & & $-0.52^{*}$ & 0.64 & & \\
\hline yield.10y.euro & & & & & & & $-0.29^{*}$ & 0.5 & & \\
\hline yield.30y.euro & & & & & & & $-0.33^{*}$ & 0.5 & & \\
\hline yield.10y.us & & & & & & & $-0.35^{*}$ & 0.45 & & \\
\hline real.export.growth.ea & & & & & & & & & $-0.02^{*}$ & 0.13 \\
\hline first.diff.yield.3y.us & & & & & & & & & $0.39^{*}$ & 0.11 \\
\hline first.diff.yield.5y.us & & & & & & & & & $0.44^{*}$ & 0.11 \\
\hline
\end{tabular}

Note: "*" denotes significance at the $1 \%$ level 
Table 4: Insurance - Factors and Macro-Variables

\begin{tabular}{|c|c|c|c|c|c|c|c|c|c|c|}
\hline 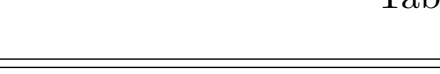 & \multicolumn{2}{|c|}{ Factor 1} & \multicolumn{2}{|c|}{ Factor 2} & \multicolumn{2}{|c|}{ Factor 3} & \multicolumn{2}{|c|}{ Factor 4} & \multicolumn{2}{|c|}{ Factor 5} \\
\hline Explained Variance & 0.17 & & 0.29 & & 0.39 & & 0.48 & & 0.56 & \\
\hline Observable & beta & $R^{2}$ & beta & $R^{2}$ & beta & $R^{2}$ & beta & $R^{2}$ & beta & $R^{2}$ \\
\hline yield.30y.us & $0.23^{*}$ & 0.41 & & & & & $0.31^{*}$ & 0.15 & & \\
\hline yield.30y.euro & $0.15^{*}$ & 0.34 & & & & & & & $0.24^{*}$ & 0.18 \\
\hline yield.10y.euro & $0.13^{*}$ & 0.33 & & & & & & & $0.22^{*}$ & 0.2 \\
\hline yield.10y.us & $0.16^{*}$ & 0.3 & & & $-0.3^{*}$ & 0.32 & & & & \\
\hline growth.rate.vix & & & $-2.24^{*}$ & 0.36 & & & $-2.06^{*}$ & 0.16 & & \\
\hline first.diff.real.export.growth.ea & & & $0.08^{*}$ & 0.28 & & & & & & \\
\hline shadow.rate.ecb & & & $-0.13^{*}$ & 0.23 & & & & & & \\
\hline first.diff.shadow.rate.ecb & & & $0.62 *$ & 0.19 & $-0.97^{*}$ & 0.36 & & & & \\
\hline yield.7y.us & & & & & $-0.26^{*}$ & 0.32 & & & & \\
\hline yield.5y.us & & & & & $-0.23^{*}$ & 0.31 & & & & \\
\hline first.diff.yield.1y.us & & & & & & & $1.01^{*}$ & 0.26 & & \\
\hline first.diff.yield.2y.us & & & & & & & $0.95^{*}$ & 0.1 & & \\
\hline first.diff.interest.rate.pigs & & & & & & & & & $1.01^{*}$ & 0.64 \\
\hline yield.5y.euro & & & & & & & & & $0.18^{*}$ & 0.17 \\
\hline
\end{tabular}

Note: "*" denotes significance at the $1 \%$ level 
Table 5: Mutual Funds - Factors and Macrovariables

\begin{tabular}{|c|c|c|c|c|c|c|c|c|c|c|}
\hline & \multicolumn{2}{|c|}{ Factor 1} & \multicolumn{2}{|c|}{ Factor 2} & \multicolumn{2}{|c|}{ Factor 3} & \multicolumn{2}{|c|}{ Factor 4} & \multicolumn{2}{|c|}{ Factor 5} \\
\hline Explained Variance & 0.20 & & 0.33 & & 0.46 & & 0.55 & & 0.62 & \\
\hline Observable & beta & $R^{2}$ & beta & $R^{2}$ & beta & $R^{2}$ & beta & $R^{2}$ & beta & $R^{2}$ \\
\hline vix & $-0.05^{*}$ & 0.57 & & & & & $0.03 *$ & 0.34 & & \\
\hline first.diff.shadow.rate.ecb & $1.11^{*}$ & 0.55 & & & & & & & & \\
\hline real.import.growth.world & $0.06^{*}$ & 0.54 & & & & & & & & \\
\hline real.trade.growth & $0.06^{*}$ & 0.5 & & & & & & & & \\
\hline shadow.rate.fed & & & $-0.12^{*}$ & 0.53 & & & & & & \\
\hline yield.1y.us & & & $-0.18^{*}$ & 0.53 & & & & & & \\
\hline yield.2y.us & & & $-0.19^{*}$ & 0.52 & & & & & & \\
\hline yield.3y.us & & & $-0.2^{*}$ & 0.5 & & & & & & \\
\hline first.diff.shadow.rate.fed & & & & & $-0.94^{*}$ & 0.54 & & & & \\
\hline first.diff.yield.1y.us & & & & & $-0.96^{*}$ & 0.39 & & & $0.93^{*}$ & 0.31 \\
\hline first.diff.interest.rate.advanced & & & & & $-1.61^{*}$ & 0.26 & & & & \\
\hline first.diff.yield.2y.us & & & & & $-0.86^{*}$ & 0.25 & & & & \\
\hline yield.30y.euro & & & & & & & $0.23 *$ & 0.54 & & \\
\hline yield.10y.euro & & & & & & & $0.19^{*}$ & 0.45 & & \\
\hline yield.5y.euro & & & & & & & $0.15^{*}$ & 0.34 & & \\
\hline shadow.rate.ecb & & & & & & & & & $-0.18^{*}$ & 0.36 \\
\hline interest.rate.advanced & & & & & & & & & $-0.35^{*}$ & 0.31 \\
\hline yield.2y.euro & & & & & & & & & $-0.18^{*}$ & 0.28 \\
\hline
\end{tabular}

Note: "*" denotes significance at the $1 \%$ level 
Table 6: Corporate - Factors and Macro-Variables

\begin{tabular}{|c|c|c|c|c|c|c|c|c|c|c|}
\hline & \multicolumn{2}{|c|}{ Factor 1} & \multicolumn{2}{|c|}{ Factor 2} & \multicolumn{2}{|c|}{ Factor 3} & \multicolumn{2}{|c|}{ Factor 4} & \multicolumn{2}{|c|}{ Factor 5} \\
\hline Explained Variance & 0.17 & & 0.30 & & 0.41 & & 0.50 & & 0.58 & \\
\hline Observable & beta & $R^{2}$ & beta & $R^{2}$ & beta & $R^{2}$ & beta & $R^{2}$ & beta & $R^{2}$ \\
\hline first.diff.interest.rate.advanced & $1.79^{*}$ & 0.58 & & & & & & & $2.32^{*}$ & 0.37 \\
\hline real.growth.rate.world & $0.17^{*}$ & 0.55 & & & & & & & & \\
\hline real.export.growth.world & $0.04^{*}$ & 0.5 & & & & & & & & \\
\hline real.trade.growth & $0.04^{*}$ & 0.49 & & & & & & & & \\
\hline real.growth.rate.ea & & & $0.2^{*}$ & 0.5 & & & & & & \\
\hline yield.1y.us & & & $0.19^{*}$ & 0.44 & & & & & $0.18^{*}$ & 0.28 \\
\hline yield.2y.us & & & $0.2^{*}$ & 0.42 & & & & & & \\
\hline yield.3y.us & & & $0.21^{*}$ & 0.4 & & & & & & \\
\hline first.diff.yield.1y.us & & & & & $1.63^{*}$ & 0.5 & $-0.94^{*}$ & 0.4 & & \\
\hline first.diff.yield.2y.us & & & & & $1.67^{*}$ & 0.44 & $-1.01^{*}$ & 0.38 & & \\
\hline first.diff.yield.3y.us & & & & & $1.57^{*}$ & 0.35 & & & & \\
\hline interest.rate.advanced & & & & & $-0.51^{*}$ & 0.35 & & & & \\
\hline first.diff.shadow.rate.fed & & & & & & & $-0.77^{*}$ & 0.39 & & \\
\hline shadow.rate.ecb & & & & & & & $0.15^{*}$ & 0.36 & $0.17^{*}$ & 0.31 \\
\hline first.diff.interest.rate.pigs & & & & & & & & & $0.73^{*}$ & 0.37 \\
\hline
\end{tabular}

Note: "*" denotes significance at the $1 \%$ level 
Table 7: Household - Factors and Macro-Variables

\begin{tabular}{|c|c|c|c|c|c|c|c|c|c|c|}
\hline & \multicolumn{2}{|c|}{ Factor 1} & \multicolumn{2}{|c|}{ Factor 2} & \multicolumn{2}{|c|}{ Factor 3} & \multicolumn{2}{|c|}{ Factor 4} & \multicolumn{2}{|c|}{ Factor 5} \\
\hline Explained Variance & 0.18 & & 0.31 & & 0.42 & & 0.52 & & 0.59 & \\
\hline Observable & beta & $R^{2}$ & beta & $R^{2}$ & beta & $R^{2}$ & beta & $R^{2}$ & beta & $R^{2}$ \\
\hline first.diff.shadow.rate.fed & $0.81^{*}$ & 0.49 & & & & & & & & \\
\hline first.diff.yield.1y.us & $0.92^{*}$ & 0.44 & & & & & & & & \\
\hline real.growth.rate.world & $0.17^{*}$ & 0.37 & $0.18^{*}$ & 0.48 & & & & & & \\
\hline first.diff.yield.2y.us & $0.93^{*}$ & 0.37 & & & & & & & & \\
\hline vix & & & $-0.04^{*}$ & 0.61 & & & & & & \\
\hline first.diff.interest.rate.advanced & & & $1.91^{*}$ & 0.47 & & & & & & \\
\hline first.diff.yield.2y.euro & & & $1.13^{*}$ & 0.44 & & & & & & \\
\hline shadow.rate.ecb & & & & & $-0.22^{*}$ & 0.34 & $-0.16^{*}$ & 0.4 & $0.17^{*}$ & 0.32 \\
\hline first.diff.interest.rate.pigs & & & & & $-0.73^{*}$ & 0.29 & $-0.6^{*}$ & 0.45 & & \\
\hline interest.rate.advanced & & & & & $-0.41^{*}$ & 0.26 & & & $0.37^{*}$ & 0.36 \\
\hline shadow.rate.fed & & & & & $-0.14^{*}$ & 0.26 & & & & \\
\hline yield.1y.us & & & & & & & $-0.15^{*}$ & 0.33 & & \\
\hline yield.2y.us & & & & & & & $-0.15^{*}$ & 0.31 & & \\
\hline first.diff.real.export.growth.ea & & & & & & & & & $-0.1^{*}$ & 0.31 \\
\hline liquidity.growth.world & & & & & & & & & $0.05^{*}$ & 0.31 \\
\hline
\end{tabular}

Note: "*" denotes significance at the $1 \%$ level 
Table 8: Public - Factors and Macro-Variables

\begin{tabular}{|c|c|c|c|c|c|c|c|c|c|c|}
\hline 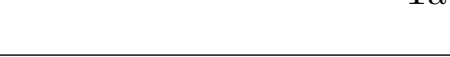 & \multicolumn{2}{|c|}{ Factor 1} & \multicolumn{2}{|c|}{ Factor 2} & \multicolumn{2}{|c|}{ Factor 3} & \multicolumn{2}{|c|}{ Factor 4} & \multicolumn{2}{|c|}{ Factor 5} \\
\hline Explained Variance & 0.21 & & 0.34 & & 0.44 & & 0.53 & & 0.61 & \\
\hline Observable & beta & $R^{2}$ & beta & $R^{2}$ & beta & $R^{2}$ & beta & $R^{2}$ & beta & $R^{2}$ \\
\hline vix & $0.03^{*}$ & 0.47 & $-0.07^{*}$ & 0.64 & & & & & & \\
\hline real.growth.rate.ea & $-0.09^{*}$ & 0.3 & & & & & & & & \\
\hline first.diff.yield.2y.euro & $-0.61^{*}$ & 0.29 & & & & & & & & \\
\hline first.diff.interest.rate.advanced & $-0.97^{*}$ & 0.27 & $3.29 *$ & 0.61 & $-1.77^{*}$ & 0.36 & & & & \\
\hline real.growth.rate.world & & & $0.32^{*}$ & 0.63 & $-0.17^{*}$ & 0.38 & & & & \\
\hline real.trade.growth.ea & & & $0.08^{*}$ & 0.56 & & & & & & \\
\hline yield.1y.us & & & & & $-0.15^{*}$ & 0.33 & & & & \\
\hline first.diff.shadow.rate.fed & & & & & $-0.68^{*}$ & 0.31 & & & & \\
\hline yield.30y.us & & & & & & & $-0.18^{*}$ & 0.17 & & \\
\hline yield.10y.us & & & & & & & $-0.13^{*}$ & 0.14 & & \\
\hline interest.rate.pigs & & & & & & & $0.06^{*}$ & 0.13 & & \\
\hline yield.7y.us & & & & & & & $-0.11^{*}$ & 0.13 & & \\
\hline yield.30y.euro & & & & & & & & & $-0.12^{*}$ & 0.24 \\
\hline yield.10y.euro & & & & & & & & & $-0.1^{*}$ & 0.22 \\
\hline interest.rate.advanced & & & & & & & & & $-0.14^{*}$ & 0.17 \\
\hline yield.5y.euro & & & & & & & & & $-0.08^{*}$ & 0.17 \\
\hline
\end{tabular}

Note: "*" denotes significance at the $1 \%$ level 
Table 9: Rest of the World - Factors and Macro-Variables

\begin{tabular}{|c|c|c|c|c|c|c|c|c|c|c|}
\hline & \multicolumn{2}{|c|}{ Factor 1} & \multicolumn{2}{|c|}{ Factor 2} & \multicolumn{2}{|c|}{ Factor 3} & \multicolumn{2}{|c|}{ Factor 4} & \multicolumn{2}{|c|}{ Factor 5} \\
\hline Explained Variance & 0.14 & & 0.25 & & 0.35 & & 0.44 & & 0.52 & \\
\hline Observable & beta & $R^{2}$ & beta & $R^{2}$ & beta & $R^{2}$ & beta & $R^{2}$ & beta & $R^{2}$ \\
\hline shadow.rate.fed & $-0.15^{\prime}$ & 0.51 & & & & & & & $-0.15^{*}$ & 0.64 \\
\hline yield.1y.us & $-0.21^{\prime}$ & 0.5 & & & & & & & $-0.2^{*}$ & 0.55 \\
\hline interest.rate.advanced & $-0.44^{3}$ & 0.48 & & & & & & & & \\
\hline yield.2y.us & $-0.22^{3}$ & 0.44 & & & & & & & $-0.21^{*}$ & 0.51 \\
\hline interest.rate.pigs & & & $0.2^{*}$ & 0.58 & & & & & & \\
\hline first.diff.yield.7y.us & & & $-1.24^{*}$ & 0.29 & & & & & & \\
\hline first.diff.yield.5y.us & & & $-1.18^{*}$ & 0.28 & & & & & & \\
\hline first.diff.yield.10y.us & & & $-1.35^{*}$ & 0.27 & & & & & & \\
\hline first.diff.interest.rate.pigs & & & & & $-0.54^{*}$ & 0.35 & & & & \\
\hline vix & & & & & $-0.02^{*}$ & 0.14 & & & & \\
\hline yield.30y.euro & & & & & -0.13 & 0.09 & & & & \\
\hline first.diff.real.export.growth.ea & & & & & -0.05 & 0.08 & & & & \\
\hline yield.2y.euro & & & & & & & $-0.28^{*}$ & 0.56 & & \\
\hline yield.5y.us & & & & & & & $-0.31^{*}$ & 0.53 & & \\
\hline yield.7y.us & & & & & & & $-0.35^{*}$ & 0.53 & & \\
\hline yield.10y.us & & & & & & & $-0.39^{*}$ & 0.51 & & \\
\hline shadow.rate.ecb & & & & & & & & & $-0.22^{*}$ & 0.71 \\
\hline
\end{tabular}

Note: "*" denotes significance at the $1 \%$ level 
Table 10: Partial and General Equilibrium Effect of a Shock to Banking Equity

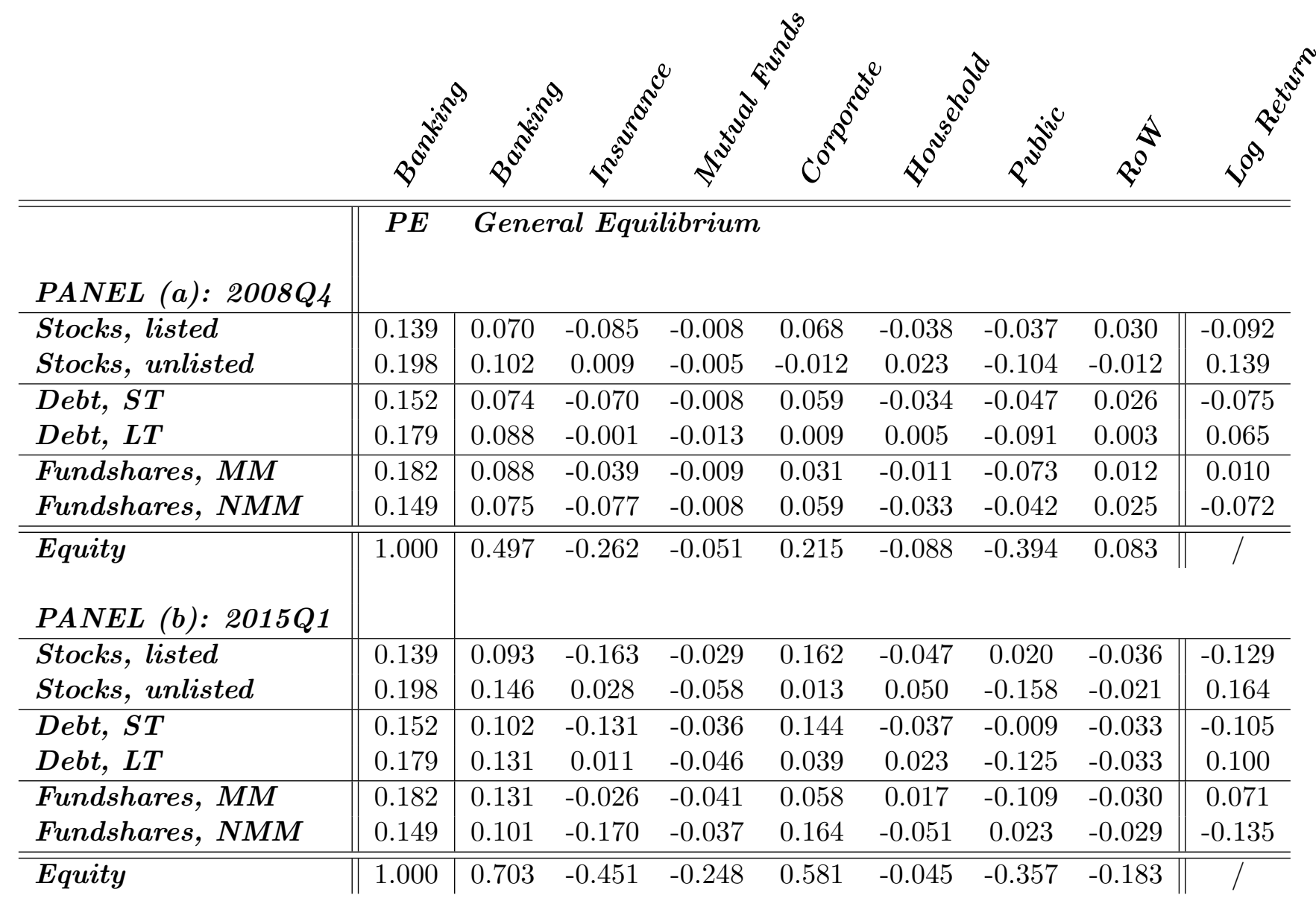




\section{A Theory - Proofs}

Proposition 2. (Existence of an Equilibrium) There exists a price vector $\mathbf{p}_{t}^{*} \in \mathbb{R}^{J}$ such that $\sum_{i=1}^{N} \boldsymbol{\Delta}_{i t}\left(\mathbf{p}_{t}^{*}\right)=\mathbf{E}_{t}\left(\mathbf{p}_{t}^{*}\right)$.

Proof. For clarity of exposition and without loss of generality, we omit the subscript $t$ in the notations for this proof. Write $\boldsymbol{\Delta}(\mathbf{p})=\sum_{i=1}^{N} \boldsymbol{\Delta}_{i}\left(p_{1}, p_{2}, \ldots, p_{J}\right)-\mathbf{E}\left(p_{1}, p_{2}, \ldots, p_{J}\right)$. Throughout the paper and following the conventions of the asset portfolio allocation literature, $\boldsymbol{\Delta}(\mathbf{p})$ is the value of net demand. We thus write $\mathbf{z}(\mathbf{p})$ the net demand in units of financial instruments, and thus $\boldsymbol{\Delta}(\mathbf{p})=\mathbf{p} \odot \mathbf{z}(\mathbf{p})$ is the term by term product of the price vector and the net demand vector in units.

An equilibrium price vector is a $J$-vector $\mathbf{p}$ such that $\mathbf{z}(\mathbf{p})=0$.

Following Mas-Colell, Whinston, Green et al. (1995), we need to show that the aggregate net demand curve $\mathbf{p} \in \mathbb{R}_{+*}^{J} \mapsto \mathbf{z}(\mathbf{p}) \in \mathbb{R}^{J}$ satisfies the following properties:

1. $\mathbf{z}(\cdot)$ is continuous.

2. $\mathbf{z}(\cdot)$ is homogenous of degree zero.

3. $\mathbf{p} \cdot \mathbf{z}(\mathbf{p})=0$ for all $\mathbf{p}$, i.e. Walras law is satisfied.

4. There is an $s>0$ such that $z_{j}(\mathbf{p})>-s$ for all financial instruments $j=1,2, \ldots, J$ and for all price vectors $\mathbf{p}$.

5. If $\mathbf{p}^{n} \rightarrow \mathbf{p}$, where $\mathbf{p} \neq 0$ and $p_{j}=0$ for some $j$, then

$$
\max \left\{z_{1}\left(\mathbf{p}^{n}\right), \ldots, z_{J}\left(\mathbf{p}^{n}\right)\right\} \rightarrow \infty
$$

The continuity of $\mathbf{z}(\cdot)$ over $\mathbb{R}_{+*}^{J}$ is established as follows. First, the variance-covariance matrix $\Sigma$ is a continuous function of the price vector of $\mathbb{R}_{+*}^{J}$. Following the assumption of section 2.1, it satisfies $\operatorname{det} \Sigma(\mathbf{p}) \neq 0$ for all $\mathbf{p} \in \mathbb{R}^{J}$ as a positive definite symmetric matrix. Thus the inverse $\Sigma^{-1}(\mathbf{p})$ is a continuous function of prices. Second, the mean return $\boldsymbol{\mu}$ is a continuous function of p. Third, the cost of equity, a rational function of $\Sigma^{-1}$ and $\boldsymbol{\mu}$ with no root in the denominator, is also a continuous function of $\mathbf{p}$.

The homogeneity of $\mathbf{z}(\cdot)$ is established by writing the expression for $\mathbf{z}(\mathbf{p})$, where $\mathbf{p}$ includes the price of shares $p_{j(i)}$ :

$$
\mathbf{z}(\mathbf{p})=\sum_{i=1}^{N} \operatorname{diag}\left(\frac{1}{\mathbf{p}}\right) \odot\left[\frac{1}{\rho} \Sigma_{i}^{-1}\left(\boldsymbol{\mu}_{i}-\eta_{i} \mathbf{1}\right)\right]
$$


where $\odot$ is the term by term vector multiplication. And $\eta_{i}=\left(\mathbf{1}^{\prime} \Sigma^{-1} \boldsymbol{\mu}-\rho p_{j(i)} \Xi_{i}\right) /\left(\mathbf{1}^{\prime} \Sigma^{-1} \mathbf{1}\right)$. Multiplying all prices by a constant $\lambda>0$ multiplies the mean returns $\boldsymbol{\mu}_{i}$ by $1 / \lambda$, multiplies the inverse of the variance-covariance matrix $\Sigma_{i}^{-1}$ by a constant $\lambda^{2}$, and the cost of equity by $\lambda$. Given the lead factor $\operatorname{diag}\left(\frac{1}{\mathbf{p}}\right)$, the net demand $\mathbf{z}(\lambda \mathbf{p})$ is unchanged, and $\mathbf{z}(\lambda \mathbf{p})=\mathbf{z}(\mathbf{p})$.

Walras law follows from the sum of the funding constraints, as

$$
\mathbf{p} \cdot \mathbf{z}(\mathbf{p})=\sum_{j=1}^{J} \sum_{i=1}^{N}\left(\Delta_{i j}(\mathbf{p})-\mathbf{1}(j(i)=j) E_{i}(\mathbf{p})\right)=0 .
$$

On point 4.: the existence of a lower bound for net demands $\mathbf{z}(\mathbf{p})$ follows from the funding constraint (1). Indeed, assume that there is no $s$ such that $z_{j}(\mathbf{p})>-s$ for all financial instruments $j=1,2, \ldots, J$ and for all price vectors $\mathbf{p}$. Then we can build a sequence $\left(s^{k}, \mathbf{p}^{k}\right)$ such that $s^{k} \rightarrow \infty$ as $k \rightarrow \infty$, and for each $k$, there is a $j^{\prime}(k)$ in $\{1,2, \ldots, J\}$ for which $-s^{k}>z_{j^{\prime}(k)}\left(\mathbf{p}^{k}\right)$. Given the funding constraint, this implies that there will be a similar sequence for which demand will go to infinity. Formally, there is a sequence $\left(\sigma^{k}, \boldsymbol{\pi}^{k}\right)$ such that $\sigma^{k} \rightarrow \infty$ as $k \rightarrow \infty$, and for each $k$, there is a $j^{\prime \prime}(k)$ in $\{1,2, \ldots, J\}$ for which $z_{j^{\prime \prime}(k)}\left(\boldsymbol{\pi}^{k}\right)>\sigma^{k}$. This, however, implies that the variance of the firm's portfolio diverges to infinity as $k \rightarrow \infty$, which cannot be a solution to the optimization program (2).

The last point follows from the fact that if asset $j$ 's return diverges to infinity, $\mu_{j} \rightarrow \infty$ and therefore according to equation (3), one of the components of net demand will diverge to infinity.

Given that properties $1-5$ are satisfied, an equilibrium price vector $\mathbf{p}^{*}$ exists with $\mathbf{z}\left(\mathbf{p}^{*}\right)=0$.

\section{B Data Appendix}

\section{B.1 Estimation of Returns from Sectoral Accounts}

There are two challenges for deriving returns on financial instrument categories from sectoral account data.

1. Returns are specific to the sectoral investment position. The sectoral accounts provide information on aggregates of financial instruments of the same type. No information exists on sectoral portfolio allocations across financial instruments of the same type. Returns realized on financial instruments of the same type therefore vary across sector, due to differences in inter-type allocations.

2. Pay-offs are recorded only at the sectoral level as income received or payed in the income 
accounts. Therefore dividends, interest payments and investment income cannot be directly attributed to financial instruments.

We use the variation of investment positions across sectors and financial instruments, the variation of valuation changes across sectors and financial instruments and the variation of income received or payed across sectors to estimate subsequently: (i) the return due to valuation changes and (ii) the return due to payoffs. Financial instruments are indexed by $j=1, \ldots, J$ and sectors are indexed by $i=1, \ldots, I$. Furthermore, $\boldsymbol{P}_{t}^{D}$ and $\boldsymbol{P}_{t}^{S}$ are matrices of size $I \times J$ that collect the demand and supply by $I$ sectors for $J$ financial instruments, respectively. The rate of return due to valuation changes is denoted by $g_{j t+1}$ and the rate of return due to payoffs is denoted by $\pi_{j t+1}$.

Assumption 1. The return on asset $j$ demanded or supplied by sector $i$ have an asset-specific component and a component specific to the financial position $f \in\{D, S\}$ of sector $i$.

$$
\begin{array}{lll}
\pi_{i j t+1}^{f} & =\pi_{j t+1}+u_{i t+1}^{f}, & f \in\{D, S\} \\
g_{i j t+1}^{f} & =g_{j t+1}+v_{i t+1}^{f}, & f \in\{D, S\}
\end{array}
$$

where $D$ denotes the demand/asset side of the balance-sheet and $S$ the supply/liability side of the balance-sheet. We assume that the component specific to the financial position $f \in\{D, S\}$ of sector $i$ is iid distributed with mean zero.

Collecting the pay-offs and valuation gains received or payed on $J$ assets by $I$ sectors in the matrices $\boldsymbol{\Pi}_{t}^{f}$ and $\boldsymbol{G}_{t}^{f}$ of dimension $I \times J$, respectively, Assumption 1 implies that the return in amount of currency units realized can be written in matrix notation as

$$
\begin{aligned}
& \boldsymbol{\Pi}_{t}^{f}=\boldsymbol{P}_{t}^{f} \operatorname{diag}\left(\boldsymbol{\pi}_{t+1}\right)+\operatorname{diag}\left(u_{t+1}^{f}\right) \boldsymbol{P}_{t}^{f}, \quad f \in\{D, S\} \\
& \boldsymbol{G}_{t}^{f}=\boldsymbol{P}_{t}^{f} \operatorname{diag}\left(\boldsymbol{g}_{t+1}\right)+\operatorname{diag}\left(v_{t+1}^{f}\right) \boldsymbol{P}_{t}^{f}, \quad f \in\{D, S\}
\end{aligned}
$$

As argued above, not all returns realized by sectors on financial instruments are fully observable. For example, only the sum of interest payments received by sector $i$ is observable, but not interest payments received on loans and coupon payments received on debt securities separately. Indeed, there are matrices $\boldsymbol{O}^{\Pi}$ and $\boldsymbol{O}^{G}$ of dimension $J \times K$ that map unobservable return components to observable functions of returns, such that we can transform equations 3031 to 


$$
\begin{aligned}
& \boldsymbol{\Pi}_{t}^{f} \boldsymbol{O}^{\Pi}=\left[\boldsymbol{P}_{t}^{f} \operatorname{diag}\left(\boldsymbol{\pi}_{t+1}\right)+\operatorname{diag}\left(u_{t+1}^{f}\right) \boldsymbol{P}_{t}^{f}\right] \boldsymbol{O}^{\Pi}, \quad f \in\{D, S\} \\
& \boldsymbol{G}_{t}^{f} \boldsymbol{O}^{G}=\left[\boldsymbol{P}_{t}^{f} \operatorname{diag}\left(\boldsymbol{g}_{t+1}\right)+\operatorname{diag}\left(v_{t+1}^{f}\right) \boldsymbol{P}_{t}^{f}\right] \boldsymbol{O}^{G}, \quad f \in\{D, S\}
\end{aligned}
$$

Note that if all returns were observable, $\boldsymbol{O}^{\Pi}=\boldsymbol{O}^{G}=\boldsymbol{I}$. Finally, we estimate $g_{j t+1}, \pi_{j t+1}$ such as to minimize the sum of squared residuals. This method simplifies to weighted Ordinary Least Squares when we assume additionally that the sector and financial position sepcific components of returns are uncorrelated.

\section{B.2 Imputation of the Real Asset}

The estimation of the model requieres information on complete balance-sheets, i.e. stock and change (valuation + flows + other changes) for both financial and non-financial assets. These data are available in the following form:

1. Financial asset stocks and changes: at quarterly frequency from quarterly sectoral accounts from EUROSTAT. The datasets are: nasq_10_f_bs, nasq_10_f_gl, nasq_10_f_tr, nasq_10_f_oc.

2. Non-financial asset stocks: at annual frequency from both EUROSTAT (nasa_10_nfa) and INSEE.

3. Non-financial asset changes to due flows: at quarterly frequency from EUROSTAT (nasq_10_nf_tr), but strangely not from INSEE.

4. Non-financial asset changes due to valuation, flows and other changes: at annual frequency from INSEE, but not from EUROSTAT.

Quarterly stocks and changes of the financial part of sectoral balance-sheet are directly obtained from the sectoral financial accounts from EUROSTAT. The non-financial part of the balance-sheet are obtained in three steps:

1. We aggregate quarterly flows from EUROSTAT to annual flows and calculate the share of the annual flow that takes place in each quarter. For example we will find that in 2008.1 $30 \%$ of the 2008 annual flow took place, etc.

2. We take annual changes (valuation + flows + other changes) from INSEE and apply the inter-annual breakdown for flows obtained in Step 1 to all types of changes. 
3. We take the annual stocks from INSEE and build up the quarterly stocks from the quarterly series of changes obtained in Step 2. 